\title{
Comparison of Seismic Response Corner Beam-Column Joint with and without Fuse Bars Under In-Plane Lateral Cyclic Loading
}

\author{
Nurfarhana Diyana Hadi ${ }^{a}$ (D) Nor Hayati Abdul Hamid ${ }^{b *}$ (D), lli Farhana Azmi ${ }^{a}$ (i), Rohana Hassan ${ }^{b}$ (D), \\ Yeri Sutopo ${ }^{c}$ (D) Bao Chao $^{d}$ (D), Nurul Azmi Zainuddine (i)
}

${ }^{a}$ Faculty of Civil Engineering, Universiti Teknologi MARA, 40450 Shah Alam, Selangor, Malaysia, E-mail: farhanadiyana88@gmail.com, ilina_azmi@yahoo.com

bInstitute For Infrastructure Engineering and Sustainable Engineering, Universiti Teknologi MARA, 40450 Shah Alam, Selangor, Malaysia,*E-mail: norha454@uitm.edu.my, rohan742@uitm.edu.my

'Department of Civil Engineering, Faculty of Engineering, Universitas Negeri Semarang, Jawa Tengah, Semarang, Indonesia 50221, E-mail: yerisutopo@mail.unnes.ac.id

dSchool of Civil Engineering and Hydraulic Engineering, Ningxia University, Yinchuan, China,

E-mail: baochao@nxu.edu.cn

eNR Link Systems Sdn Bhd, SW-03A-18, Cova Square, Jalan Teknologi PJU 5, Kota Damansara, 47810 Petaling Jaya, Selangor, Malaysia, E-mail: nurulazmi@nrlink.com.my

*Corresponding author

https://doi.org/10.1590/1679-78256581

\begin{abstract}
Two full-scale corner beam-column joints with and without fuse bars were designed, constructed, tested, analyzed and modeled under in-plane lateral cyclic loading presented herein. The first specimen was designed using Eurocode 8 and equipped with four fuse bars. Second specimen was designed using BS8110 (non-seismic code of practice) with corbel. All the specimens have similar size of foundation beams, columns and beams. Visual observation during testing showed that specimen with fuse bars suffered less damage as compare with specimen without fuse bars. Furthermore, specimen with fuse bars has higher lateral strength capacity, stiffness, ductility and equivalent viscous damping than specimen without fuse bars. Finally, there is good agreement of lateral strength capacity, ductility, stiffness and equivalent viscous damping which lies between $2 \%$ and $20 \%$ between experiment and modeling hysteresis loops. Thus, it is recommended that fuse bar as a green structural material can be installed inside the corner beam-column joint for RC buildings to cater strong earthquakes in high seismic regions.
\end{abstract}

\section{Keywords}

corner beam-column joint, fuse bars, hysteresis loops, ductility, green material

\section{Graphical Abstract}
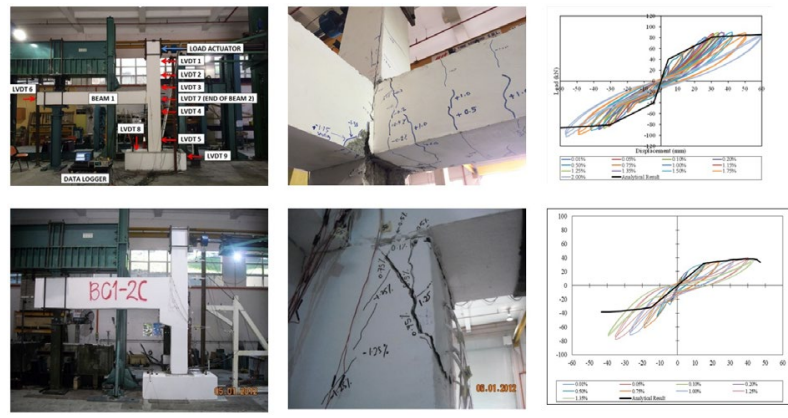

Received June 01, 2021. In revised form October 05, 2021. Accepted November 17, 2021. Available online November 26, 2021. https://doi.org/10.1590/1679-78256581

(c) (i) Latin American Journal of Solids and Structures. ISSN 1679-7825. Copyright (C 2021. This is an Open Access article distributed under the terms of the Creative Commons Attribution License, which permits unrestricted use, distribution, and reproduction in any medium, provided the original work is properly cited. 


\section{INTRODUCTION}

The ability of a seismic structure to withstand earthquake load relies heavily on the design of the structure itself using seismic code of practice. Seismic design focuses on optimizing the global ductile behavior of a structure. Ductile design enables the structure to undergo inelastic deformations while most of the energy is dissipated through hysteretic behavior. In order to achieve 'capacity design' principles whereby areas are not intended to contribute to the inelastic response are 'over-designed' with respect to areas where inelastic deformations are intended. However, some researchers argued that it is necessary for such requirement when there are more economical and better solutions available [1]. This applies especially to regions with low to medium magnitude of earthquake in moderate seismic regions. By adding Earthquake Protective System (EPS) to new or existing buildings is one of the ways to reduce structural damages during earthquakes. EPS can be divided into three types namely Passive Protective Systems, Hybrid Protective Systems and Active Protective Systems [2]. Seismic fuse bars also known as mechanical energy dissipators are made from high yield reinforcement bars by trimming and reduce the diameter at mid-span which classified as Passive Protective Systems. There are various types of seismic fuse bars and it can be applied to different types of structures such as wall, concrete frame, steel frame, and also beam-column joint [3-6]. Most common structural fuse were used in frame and connections are plates $[7,8]$ and bars to resist the earthquake loads $[9,10]$.

A lot of studies have been conducted on non-seismic beam-column joint and the factors that contribute to the structures failures. Structural damage or failure modes are expected to occur in beam-column joints depending on the types of joint and structural detailing [11]. Laboratory testing for non-seismic RC exterior tee beam-column joints subjected to in-plane lateral cyclic loading showed the joint failures and formation of plastic hinge zone in the column [12-14]. This is evident that non-seismic design buildings are very vulnerable under seismic load includes the buildings in Malaysia. Most of the reinforced concrete in Malaysia were designed and constructed using non-seismic code of practice known as BS8110. An experimental work on super-assemblages of precast corner beam-column joint with corbel of a two-story school building prototype which designed in accordance to BS8110 was tested under in-plane lateral cyclic loading [15]. There were a lot of vertical and diagonal cracks at joint and top of column due to soft-story mechanism. Therefore, the intention of this study is to compare the seismic performance of corner beam-column joint with and without fuse bars under in-plane lateral cyclic loading. The corner beam-column joint will be designed using Eurocode 8 with fuse bars are placed at the middle of the joint. Fuse bars is considered as a green infrastructure material which can be used to resist earthquake effectively with minimum cost by using the high yield reinforcement bars. Furthermore, fuse bars also can be replaced after the earthquake if they are yielding and buckling with minimum cost. The comparison of seismic performance and modeling of corner beam-column joint with and without fuse bars will be presented in the following section.

\section{A PROTOTYPE OF REINFORCED CONCRETE BUILDING}

Beam-column joints are very important structural components in RC buildings to transfer the load to the foundation beam and it is a crucial zone for the moment-resisting frame. In this study, the beam-column joints were designed and constructed based on an existing two-story Industrialized Building System (IBS) school building. Figure 1 shows side elevation of the two-story prototype building for this study with total height of $7 \mathrm{~m}$, each floor has $3.5 \mathrm{~m}$ height and width of $6 \mathrm{~m}$. The corner joint of this building will be designed using Eurocode 8 [17] and fuse bars are used as mechanical energy dissipator to cater for peak ground acceleration ( $P G A=0.12 \mathrm{~g}$ ).

\section{DESIGN FUSE BARS AND BEAM-COLUMN JOINTS}

The safety of reinforced concrete (RC) building during earthquake depends on the ductility of the structural system and its ability to resist seismic load. Ideally, a ductile structure experiences a large deformation without any structural elements failure during earthquake. But, it is not practical to design a RC building with all structural elements fully ductile because it is very costly to build it using a lot of reinforcement bars. Hence, it is recommended to design a ductile structure with both ductile and brittle elements [18]. Under ductile design, the RC buildings should undergo inelastic deformation by dissipating most of the seismic energy through its hysteretic behaviour [19]. Moreover, the seismic design must also provide adequate lateral strength capacity to resist earthquake excitations while maximizing the global ductile behavior of a structure known as 'capacity design principles'. The capacity design principle using the "chain model" where the chain represents a structural system with ductile elements (ductile link, 1) and brittle zones (brittle link, i) as shown in Figure 1(a) [16]. The ductile link is representing by energy dissipators such as passive mechanical energy dissipator, fuse bar, semiactive viscous damper and base isolation. In this study, the ductile link is substituted by fuse bars which positioned inside 
corner beam-column joint. Meanwhile, the brittle link is signifying by structural elements such as beam-column joint, column, beam, slab, wall and others as shown in Figure 1(b) where $F$ a force is applied to both ends of the chains and transferred through all the links in the chain. When huge force such as seismic load imposed to the structure, the weakest link in the chain will break and collapse. If the ductile link is the weak one, then the chain will show large deformation. However, if the brittle link is the weak one, then the chain will fail suddenly with small deformation. Therefore, by applying the capacity design principle and maximum feasible strength in the plastic regions can be reached which results in all 'brittle' structural components being protected against failure. Figure 1(c) shows the load versus displacement for ductile link, brittle link and the combination of these links. The elastic behaviour can be obtained in brittle link and the non-linear can be obtained in ductile link. The combination of these links will produce higher ductility where yield displacement, ultimate displacement and forces are bigger and can cater earthquake load.

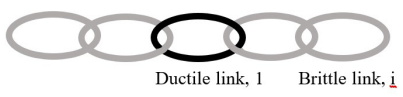

(a) The ductile chain at rest

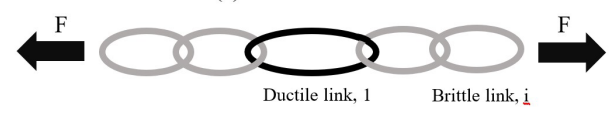

(b) Loaded ductile chain

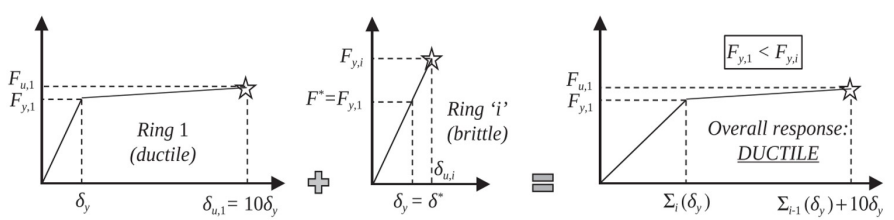

(c) Elastic behavior of the ductile chain

Figure 1: Ductility of a chain with brittle and ductile links [16].

The ductile link which representing fuse bar is embedded inside beam-column joint and it made from high yield reinforcement bar with a reduction of diameter at a specific designed length to create a ductile region. This region was considered as the ductile link in the beam-column joint to ensure more energy dissipated through it. The main advantage of using fuse bar is that it can be placed under both tension and compression zone depending on the connecting system [20]. Furthermore, it is also can be replaced after the earthquake if the fuse bars are located outside the beam-column joint. Figure 2(a) shows the total length of the fuse bar $\left(l_{\mathrm{fb}}\right)$ is $600 \mathrm{~mm}$ and the unbonded reduced section $\left(l_{\mathrm{ub}}\right)$ was $200 \mathrm{~mm}$ which located at the middle part of the bar. $A$ total number of four high yield bar with diameter of $16 \mathrm{~mm}\left(f_{y}=500 \mathrm{~N} / \mathrm{mm}^{2}\right)$ were machined down to a reduced diameter of $13 \mathrm{~mm}$ to create a "dog-bone". In this study, the reduced diameter of $13 \mathrm{~mm}$ was chosen because the corner beamcolumn joint can cater less lateral seismic load as compare to exterior and interior beam-column joint. Meanwhile, Figure 2(b) shows actual size of fuse bars after milling its center. These four fuse bars need to implant inside the corner beam-column joint. The numbers of fuse bars and size of reduced diameter substantially influence the lateral strength capacity of beam-column joint under earthquake excitations.

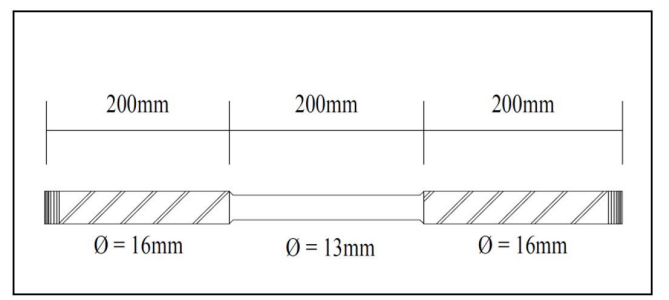

(a) Plan view and dimension of a fuse bar

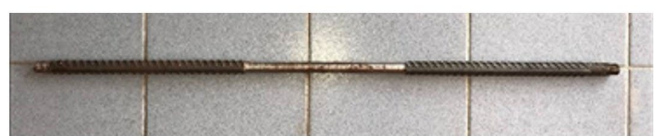

(b) The actual size of fuse bar and $13 \mathrm{~mm}$ diameter at middle part after trimming it.

Figure 2: (a) plan view and dimension of fuse bars and (b) actual size of fuse bar. 
After completing designing and making fuse bars, two types of corner beam-column joints were designed, constructed and tested under quasi-static in-plane lateral cyclic loading. In order to design corner beam-column joint, a prototype two-story RC building was chosen for this study. Figure 3 shows the side elevation of the prototype building and location of corner beam-column joint is marked in red circle. The first full-scale specimen of corner beam-column joint was designed using Eurocode 8 under Ductility Class Medium (DCM) to cater peak ground acceleration (PGA) of $0.12 \mathrm{~g}$ where $\mathrm{g}$ is the acceleration of gravity ( $\mathrm{g}=9.81$ $\mathrm{m} / \mathrm{s}^{2}$ ). This specimen was equipped with fuse bars which acting as energy dissipator to absorb the earthquake energy and simultaneously reduce the structural damages of RC buildings. Figure 4(a) shows the super-assemblage of corner beam-column joint with fuse bars which labeled as $\mathrm{CJ}-2 \mathrm{~B}$ specimen. Fuse bars marked in red color were welded to the steel plate and positioned at one edge of the corners. It is important to determine the effectiveness of the fuse bars in terms of lateral strength capacity, stiffness, ductility and equivalent viscous damping in the joints. Thus, the second full-scale specimen without fuse bars was designed using British Standard (BS8110) which is non-seismic code of practice and compare with the first specimen. Consequently, Figure 4(b) exhibits the corbel beam-column joint without fuse bars labeled as BC1-2C specimen. This specimen consists of a foundation beam, one column with two corbels, one in-plane beam and one out of plane beam. The corbels were designed to support these beams and to cater shear forces which came from dead and imposed loads.

\section{CONSTRUCTION OF CJ-2B AND BC2-3I SPECIMENS}

The construction of super-assemblage full-scale corner beam-column joints with and without fuse bars were took place at Heavy Structural Laboratory, School of Civil Engineering, Universiti Teknologi MARA, Shah Alam, Selangor, Malaysia. The first specimen labeled as CJ-2B was started with construction of foundation beam with dimensions of $1800 \times 900 \times 500 \mathrm{~mm}$ with eight numbers of $50 \mathrm{~mm}$ vertical holes which used to clamp the foundation beam to the strong floor. Then, the column stump was built at the middle of the foundation beam using $16 \mathrm{~mm}$ diameter of high yield reinforcement bars and plywood as the formwork. Upon completion of the bottom column, the construction of $\mathrm{CJ}-2 \mathrm{~B}$ specimen was commenced by installing a total number of eight fuse bars inside the joint. Figure 5(a) shows the installation of four fuse bars at the top and another four located at bottom (red arrow) using mechanical coupler to connect the fuse bars with the longitudinal reinforcement bars in the out-of-plane beam. The other ends of fuse bars were welded to the steel plate positioned at end of the beam.

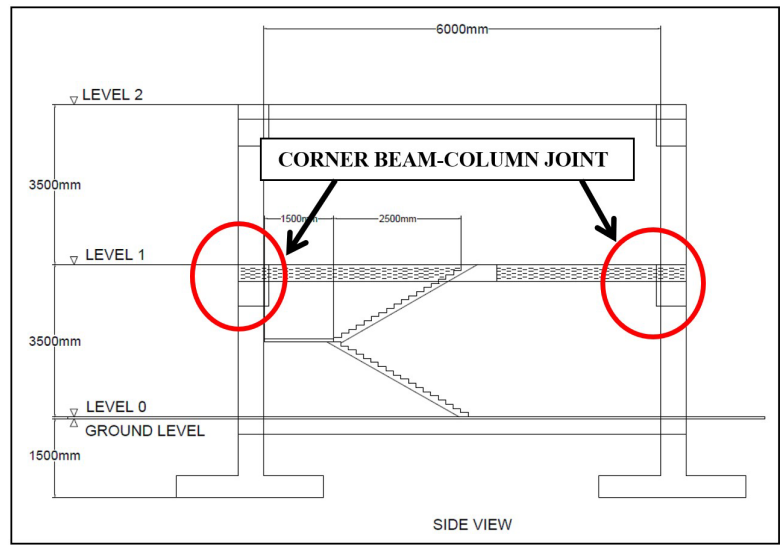

Figure 3: Side elevation of a prototype two-story precast school building

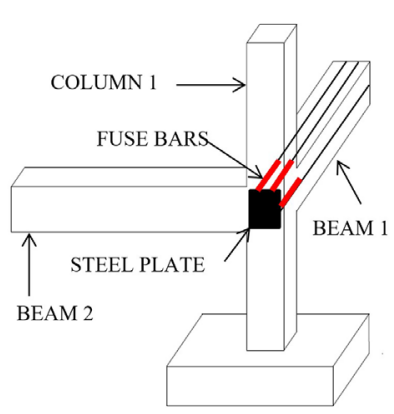

(a) Corner beam-column with fuse bars and labelled as CJ-2B specimen

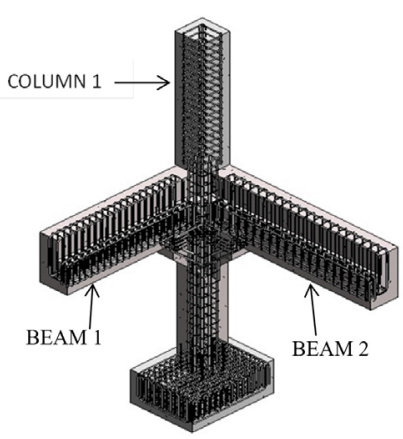

(b) Corner corbel beam-column joint without fuse bars and labelled as $\mathrm{BC} 1-2 \mathrm{C}$ specimen

Figure 4: Three dimension of beam-column joint with and without fuse bars 
The construction of corner beam-column joint with fuse bars is considered as economical, safe under moderate earthquakes and it is a green infrastructure material which can be reused or replace again after the earthquakes. Furthermore, fuse bars can be made in the fabrication laboratory with minimum cost as compare in buying special base isolation to cater for moderate seismic load. Meanwhile, Figure 5(b) shows the construction of formwork for the two beams and one top column of $\mathrm{CJ}-2 \mathrm{~B}$ specimen where the in-plane lateral cyclic loading was applied on its top.

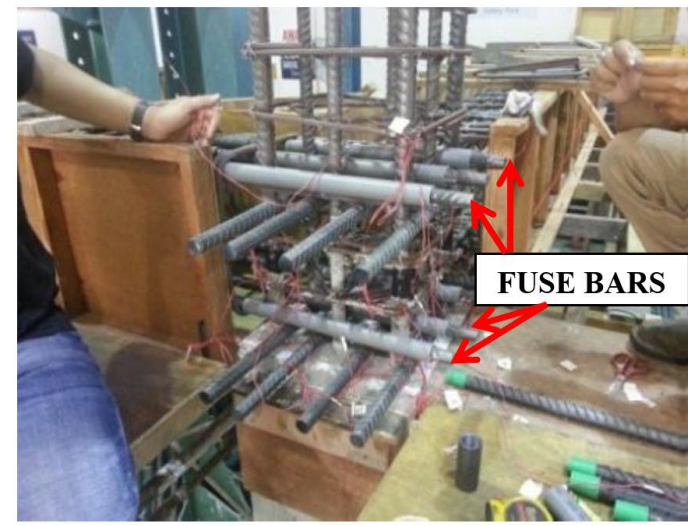

(a) Installation of fuse bars inside the joint

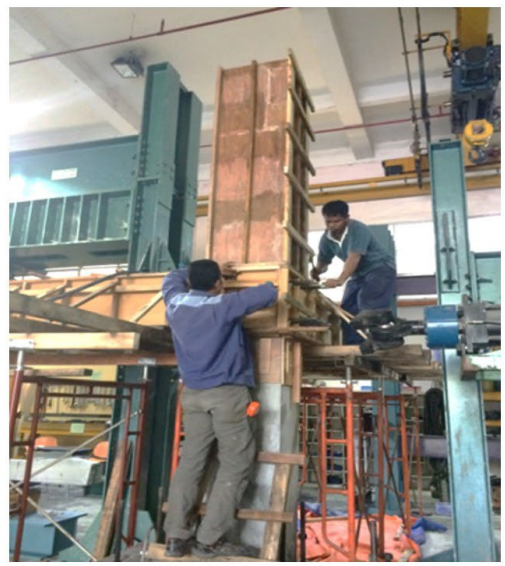

(b) construction of corner beam-column joint

Figure 5: Construction of corner beam-column joint with fuse bars labeled as CJ-2B specimen

The second specimen with fuse bars which labeled as BC1-2C was designed and constructed to cater for in-plane lateral cyclic loading similar with the first specimen. Figure 6 shows the overall construction of BC1-2C specimen on top of the foundation beam. Figure 6(a) shows the assemblage of corner joint comprises of in-plane beam, out-of-plane beam and top column. Two numbers of corbels were attached to bottom column with red arrows were designed to support the beams. Figure 6(b) shows the overall corner joint constructed on top of foundation beam which is clamped to the strong floor before testing of the specimen under in-plane lateral cyclic loading took place.

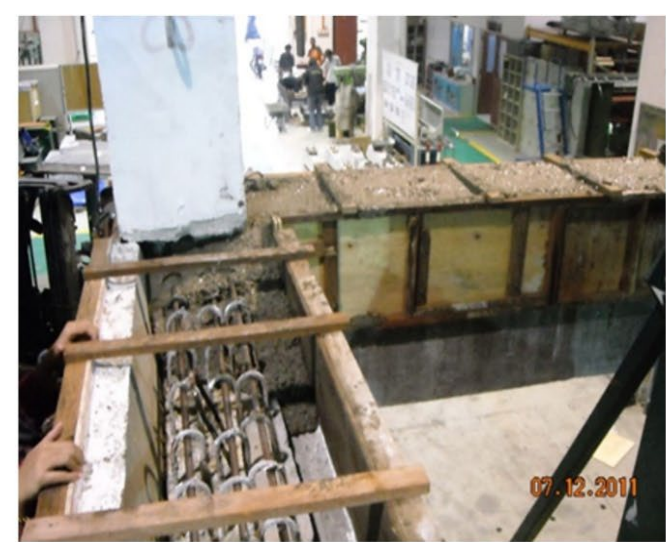

(a)construction of in-plane and out-of-plane beam and top column

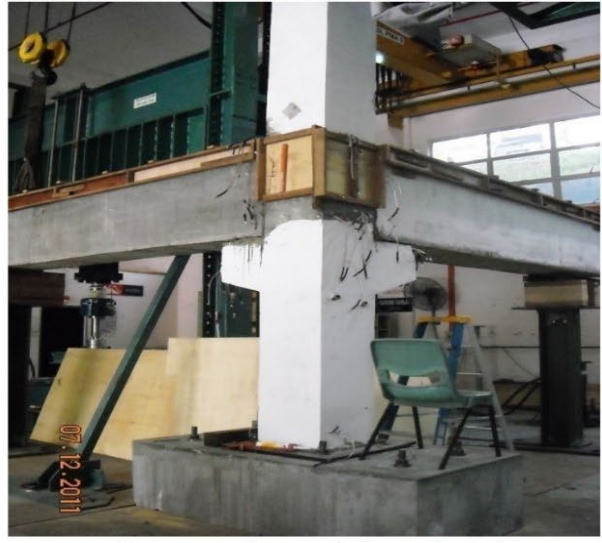

(b) corner beam-column joint placed on top of the foundation beam

Figure 6: Construction of corner beam-column joint without fuse bars labeled as $\mathrm{BC} 1-2 \mathrm{C}$ specimen

\section{INSTRUMENTATION AND EXPERIMENTAL SET-UP}

Both of BC1-2C and CJ-2B specimens with two perpendiculars beams and column were tested under in-plane lateral cyclic loading using $500 \mathrm{kN}$ dynamic double actuator. This process involved the preparation of loading regime, calibration of linear potentiometers (LVDT) and data logger. Figure 7(a) shows a systematic arrangement of LVDTs, data logger and load actuator at top of the column before testing the CJ-2B specimen with fuse bars under quasi-static in-plane lateral cyclic loading. The distances and locations of all the LVDTs which used to measure the lateral displacement of CJ-2B 
specimen and foundation beam are tabulated in Table 1. The loading protocol used in this study is the norm ASTM E212611. These test methods cover the evaluation of the shear stiffness, shear strength, and ductility of the vertical elements of lateral force resisting systems, including applicable shear connections and hold-down connections, under quasi-static cyclic (reversed) load conditions. The horizontal forces are applied under controlled cyclic displacement until the lateral strength capacity decreases $85 \%$ of the peak horizontal loads. Force and displacement controlled method were used to test the specimen under quasi-static in-plane lateral cyclic loading. The force controlled method applied until yield strength achieved and displacement control method used when the specimen behaved under nonlinear behavior. Figure 7 (b) exhibits the loading regime with numbers of cycles to be tested under in-plane lateral cyclic loading. For each target displacement, two cycles of loading will be imposed to the specimen after yielding until its failures. The testing under quasi-static loading means that the load is applied slowly that the structure deforms very slowly so that the hairline cracks can be marked and visual observation on opening and closing gap of the cracks can be seen clearly. This test is independent of time and its inertia force is very small and can be ignored. The in-plane lateral load was supplied by the load cell which attached to the double actuator located at the top of the column as shown in Figure 7(a). The rate of loading under elastic limit was $0.083 \mathrm{~mm} / \mathrm{s}$ and after yielding the rate was $0.222 \mathrm{~mm} / \mathrm{s}$. The frequencies under elastic limit and plastic limit were $0.0167 \mathrm{~Hz}$ and $0.00555 \mathrm{~Hz}$, respectively. The loading rate and frequency were chosen based on the amount of lateral displacement applied to the structure. When the lateral displacement increases, the loading rate increases but the frequency reduces. The rate of loading and frequency which supplied by the double actuator did not represent the real condition of earthquake. The actual earthquake excitation can be imitated by using shaking table. Due to this limitation and the size of specimens were very huge, the experimental work and experimental set-up were conducted in strong floor in heavy structures laboratory.

Table 1: Distances and locations of LVDTs from strong floor

\begin{tabular}{ccc}
\hline No & Name of Instrument & Height from strong floor $(\mathrm{mm})$ \\
\hline 1. & LVDT1 & $3600 \mathrm{~mm}$ \\
2. & LVDT2 & $3100 \mathrm{~mm}$ \\
3. & LVDT3 & $2600 \mathrm{~mm}$ \\
4. & LVDT4 & $1450 \mathrm{~mm}$ \\
5. & LVDT5 & $550 \mathrm{~mm}$ \\
6. & LVDT6 (end of BEAM 1) & $2375 \mathrm{~mm}$ \\
7. & LVDT7 (end of BEAM 2) & $2375 \mathrm{~mm}$ \\
8. & LVDT8 & $500 \mathrm{~mm}$ \\
9. & LVDT & $250 \mathrm{~mm}$ \\
\hline
\end{tabular}

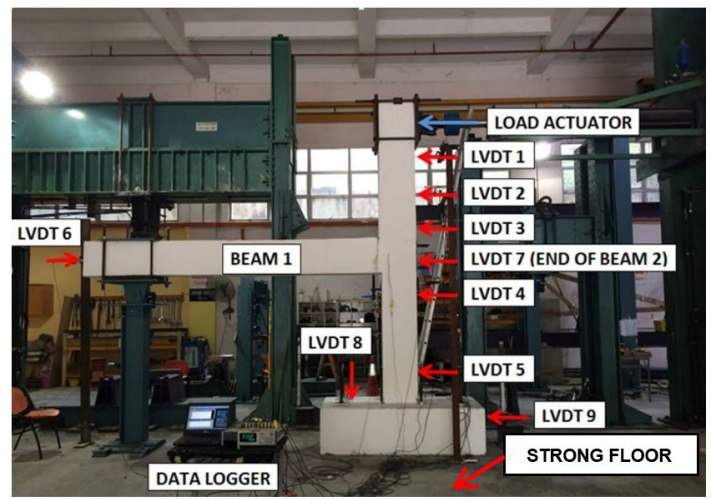

(a) Installation of LVDTs at column and beams

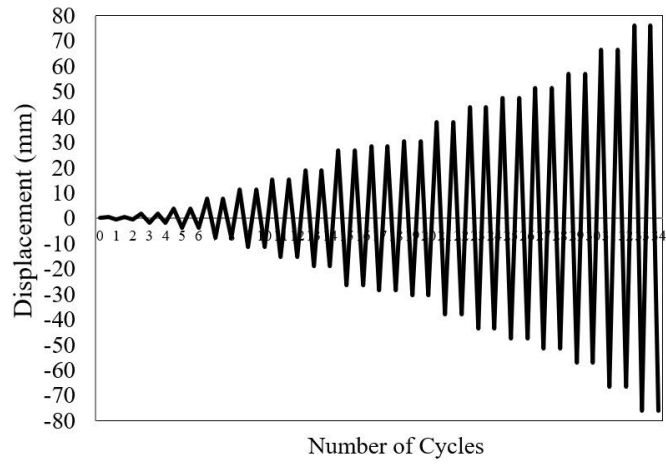

(b) Loading regime with number of cycles

Figure 7: Instrumentation and set-up together with loading regime for $\mathrm{CJ}-2 \mathrm{~B}$ specimen

The second specimen without fuse bars labeled as $\mathrm{BC} 1-2 \mathrm{C}$ was tested under in-plane lateral cyclic loading using similar loading protocol and distances of LVDTs from strong floor as shown in Table 1. Figure 8(a) illustrates the three dimensions of the $\mathrm{BC} 1-2 \mathrm{C}$ specimen without fuse bars together with its instrumentation and equipment which is ready for testing. Meanwhile, Figure $8(\mathrm{~b})$ demonstrates the loading regime with a series number of cycles to be tested under 
in-plane lateral cyclic loading. The in-plane lateral displacement of the specimen which measured by LVDTs can also converted into percentage drift as shown in Equation 1.

Percentage Drift $(\%)=\frac{\text { In-plane Lateral Displacement }(\mathrm{mm}) \times 100}{\text { Effective Height }(\text { Heff })(\mathrm{mm})}$

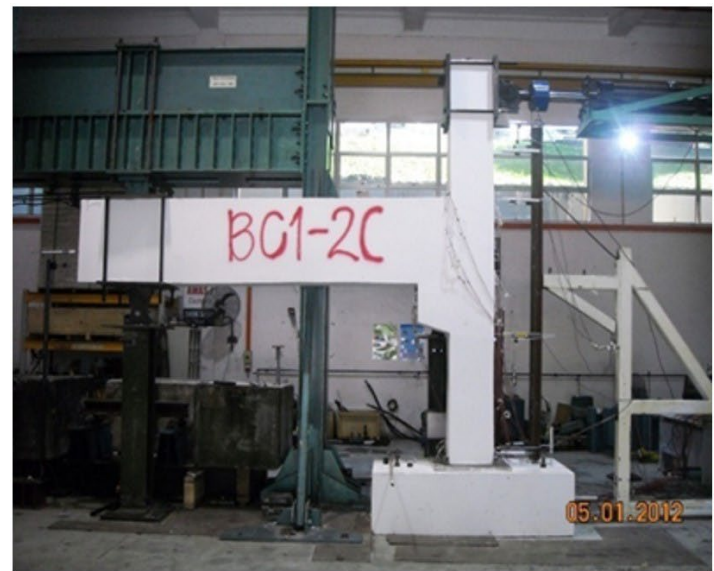

(a) Front view of specimen with fuse bars is ready for testing.

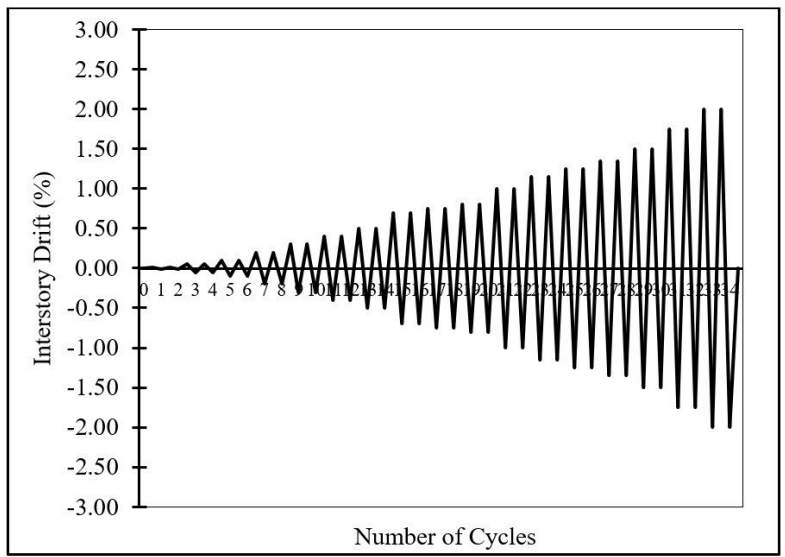

(b) Loading regime with numbers of cycles.

Figure 8: Instrumentation and set-up for $\mathrm{BC} 1-2 \mathrm{C}$ specimen without fuse bars and loading regime

\section{EXPERIMENTAL RESULTS AND ANALYSIS}

\subsection{VISUAL OBSERVATION OF CRACKS}

The visual observation of the cracks width, cracks propagation and spalling of the concrete covers corresponding with different level of drifts are among the structural damages that need to pay attention during testing both of the specimens. Figure 9(a) shows the closing and opening gap of cracks at the beam-column interface up to $1.50 \%$ drift where location of the plastic hinge zone occurred for CJ-2B with fuse bars placed inside the joint. Figure 9(b) exhibits the spalling of concrete cover underneath the beam and column's surface at $2.0 \%$ drift. CJ-2B specimen was successfully tested up to $2.0 \%$ drift with $4 \mathrm{~mm}$ crack width and vertical cracks along the beam and minor damage at the beam-column joint. Contradictory, Figure 10(a) exhibits transverse cracks of $425 \mathrm{~mm}$ in length and $10 \mathrm{~mm}$ cracks width at corbel of BC1-2C Specimen up to only $1.35 \%$ drift only. Figure 10(b) demonstrates the diagonal cracks of $295 \mathrm{~mm}$ in length and an $8 \mathrm{~mm}$ opening of the gap occurred at the top edge of corbel. It is clearly seen that the beam-column joint with fuse bars can withstand higher drift than joint without fuse bars.

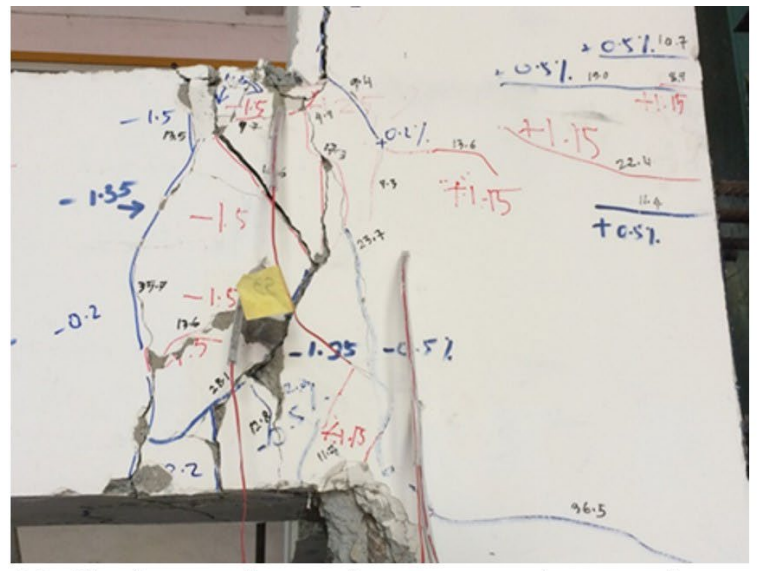

(a) Closing and opening gap at beam-column interface up to $1.50 \%$ drift.

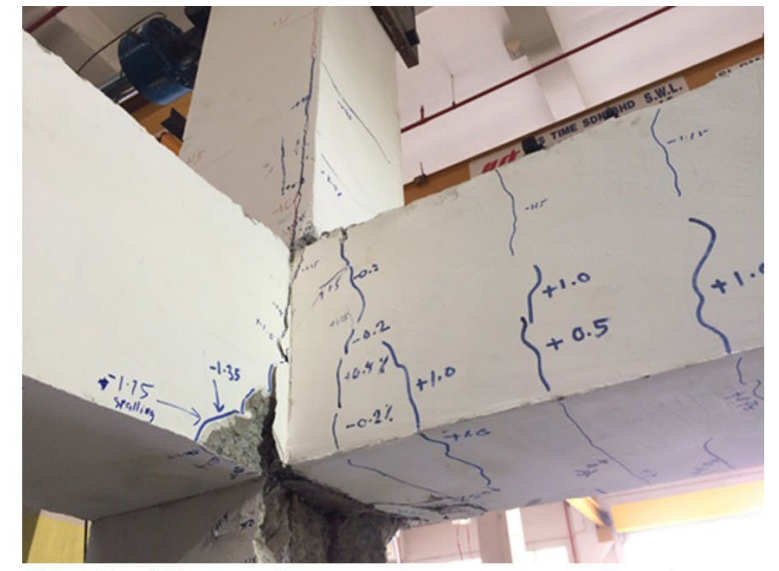

(b) Spalling of concrete cover near beamcolumn interface at $2.0 \%$ drift

Figure 9: Visual observation of cracks and spalling of concrete at $1.50 \%$ and $2.0 \%$ drift for $\mathrm{CJ}-2 \mathrm{~B}$ specimen with fuse bars 


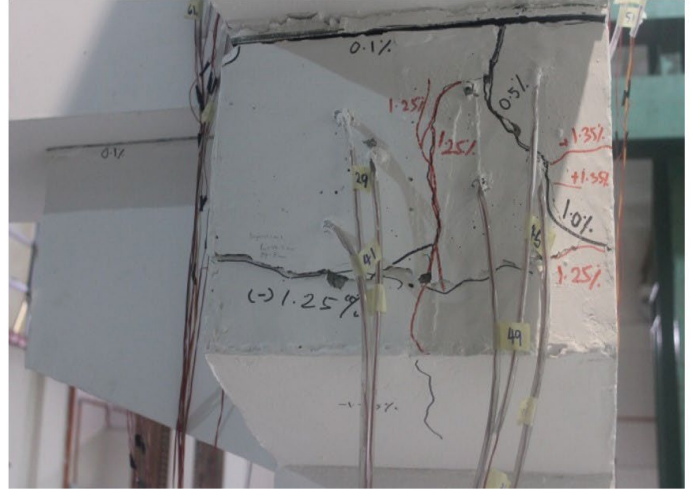

(a) Transverse cracks of $425 \mathrm{~mm}$ in length and cracks width of $10 \mathrm{~mm}$.

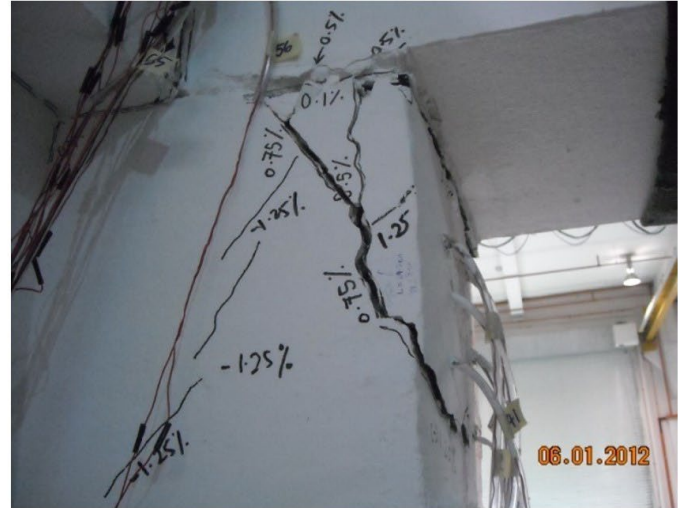

(b) Diagonal cracks of $295 \mathrm{~mm}$ in length and an $8 \mathrm{~mm}$ opening of the gap occurred at the corbel

Figure 10: Closing and opening of the gap occurred on BC1-2C Specimen at $\pm 1.35 \% \mathrm{drift}$.

\subsection{COMPARISON OF HYSTERESIS LOOPS}

The graph hysteresis loops can be obtained by plotting load versus displacement for each drift applied to these two super-assemblage specimens. In order to determine the efficiency and seismic performance of corner beam-column joint with fuse bars, the hysteresis loops with and without fuse bars were compared between them. The hysteresis loops of CJ-2B Specimen were plotted based on data obtained from LVDT1 where it was positioned the closest to double actuator. Figure 11(a) presents the hysteresis loops and the derived analytical curve (pushover curve) CJ-2B specimen with fuse bars up to $2.0 \%$ drift. The analytical result for $\mathrm{CJ}-2 \mathrm{~B}$ specimen has fairly good agreement with the experimental result. For the meantime, Figure 11(b) shows the hysteresis loops of BC1-2C specimen and analytical curve which derived based on Monolithic Beam Analogy (MBA). By comparing Figure 11(a) and Figure 11(b), the BC1-2C specimen has the maximum drift of $1.35 \%$ drift while CJ-2B Specimen has maximum drift of $2.00 \%$ drift. Secondly, the hysteresis loops with fuse bars have symmetrical lateral strength capacity whereas hysteresis loop without fuse bars have unsymmetrical shape. Thirdly, the lateral strength capacity joint with fuse bar has twice lateral strength in pushing direction than without fuse bars. Therefore, it can be concluded that corner joint with fuse bars can sustain higher drift and lateral strength capacity as compared with corner joint without fuse bars.

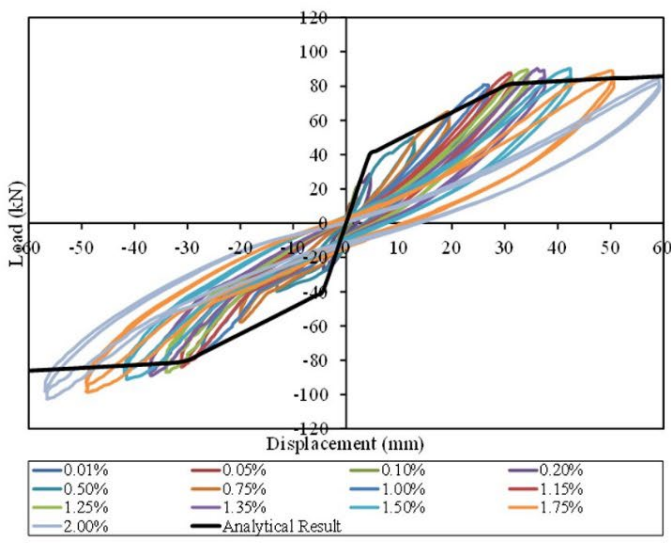

(a) Hysteresis loops for CJ-2B specimen

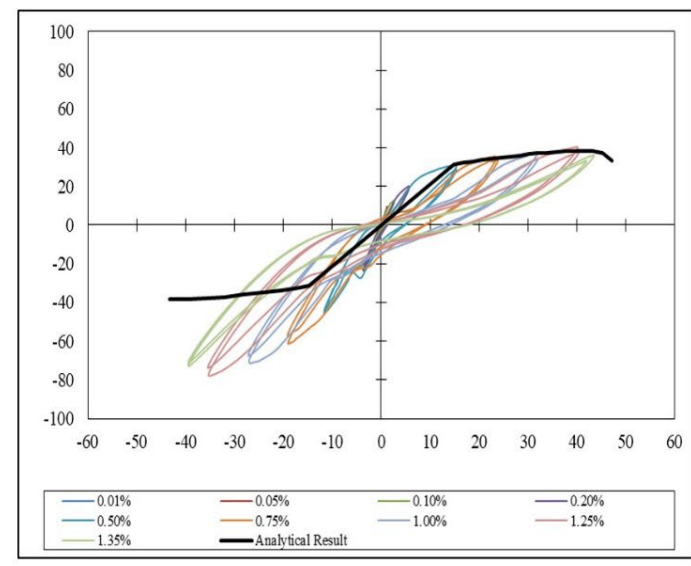

(b) Hysteresis loops for BC1-2C Specimen

Figure 11: Comparison of hysteresis loops for corner beam-column joint with and without fuse bars

There are six steps in developing and deriving the analytical curve or pushover analysis for $\mathrm{CJ}-2 \mathrm{~B}$ and $\mathrm{BC} 1-2 \mathrm{C}$ specimens as shown in Figure 11(a) and Figure 11(b) using Monolithic Beam Analogy (MBA) approach. The details of the step-by-step procedures and derivations of equations involve in this approach are explained as follows:

Step 1: Fix the rotation, $\theta_{b}$

The effective rotation, $\theta_{b}$ is developed at the beam-column interface due to the opening of the crack is related to the drift of the framing system with simple geometric considerations as shown in Figure 12. Equation 2 shows the beam rotation and inter-storey drifts relationship in beam-column joint. 
$\theta_{b}=\frac{\theta}{1-\frac{h_{c}}{l}}$

Where $h_{c}$ is column depth, $\theta$ is column rotation (average of story drifts above and below the floor level) and $/$ is beam ideal length between centre to centre of beam-column joints.

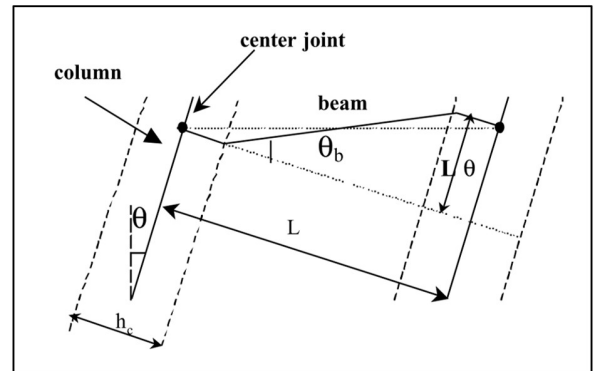

Figure 12: Interstory drifts-beam rotation relationship between two beam-column joints.

Step 2: Guess an initial neutral axis depth, $c$ for the beam.

Step 3: Estimate the strain in fuse bars, reinforcement bars and concrete. The strain in unbonded fuse bar $\left(\varepsilon_{f}\right)$ due to the beam deformation is given in Equation 3 below:

$\varepsilon_{f}=\frac{n \cdot \Delta_{f}}{l_{u b}}$

Where $n$ is number of total openings along the beam-column interfaces, $I_{u b}$ is unbonded length of the fuse bars and $\Delta_{f}$ is the elastic and plastic elongation at fuse bars. By rearranging Equation 2 and Equation 3 gives $\Delta_{f}$ and is represented by Equation 4.

$\Delta_{f}=\theta\left(\frac{h}{2}-c\right)$

Where $h / 2-c$ is the relative position of the fuse bars which assumed to be at mid-height of the section and $h$ is the beam section height.

The strain in high yield steel reinforcement can be derived from the gap opening mechanism as shown in Figure 13. The strain in the main reinforcement bar can be calculated as follows:

$\varepsilon_{\mathrm{s}}=\frac{\Delta-2 \Delta_{\mathrm{sp}}}{l_{u b}}$

Where $\Delta$ is the elongation at the level of the fuse bars due to the opening of the crack and $\Delta_{\text {sp }}$ is the displacement due to strain penetration. $\Delta$ is given by Equation 6 as follows:

$\Delta=(d-c) \theta$

Where $d$ is the beam section depth. The contribution in $\Delta$ due to strain is given in Equation 7 and the strain in reinforcement bars is given by Equation 8 as follows:

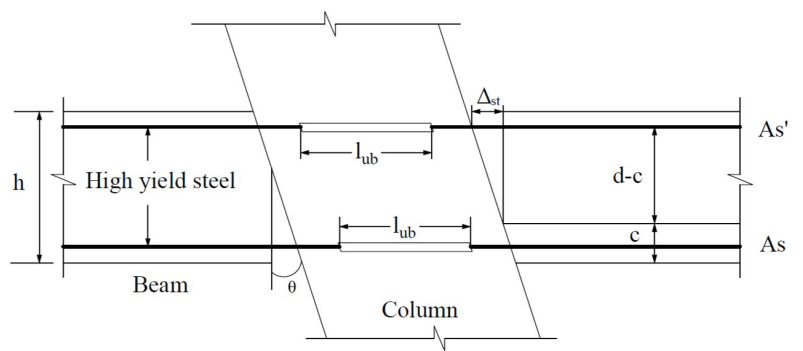

Figure 13: Gap opening mechanism in the beam-column joint interface 
$\Delta_{s p}=l_{s p} \varepsilon_{p}+\frac{2}{3} l_{s p} \varepsilon_{e}$

$\varepsilon_{p}=\varepsilon_{s}-\varepsilon_{e}$

Rearranging Equation 8, it gives the strain in reinforcement steel as shown in Equation 9:

$\varepsilon_{s}=\frac{\left(\Delta+2 / 3 l_{s p} \varepsilon_{e}\right)}{\left(l_{u b}+2 l_{s p}\right)}$

Where the elastic strain, $\varepsilon_{\mathrm{s}}$ is represented by Equation 10 as follows:

$\varepsilon_{e}=\frac{f_{s t}}{E_{s}}$

Where $f_{s t}$ is the elastic stress corresponding to $\varepsilon_{s}$ and $E_{s}$ is the elastic modulus of the reinforcement bar.

The strain in concrete is calculated based on Monolithic Beam Analogy (MBA) concept where the monolithic joints are assumed to have a similar behaviour as the precast joints. The concept was developed to ensure member compatibility between the two joints with the same geometry and materials. In this step, the end displacement for a monolithic joint $\left(\Delta_{\text {monolithic }}\right)$ is assumed to have the same value to end the displacement of a precast joint $\left(\Delta_{\text {precast }}\right)$. Figure 14 shows the diagram of precast ductile connection and monolithic connection as developed by (Pampanin, 2003). Equation 11 represents the total displacement equivalent for monolithic and precast beams.

$\Delta_{\text {elastic }}+\Delta_{\text {imp }}=\Delta_{\text {elastic }}+\Delta_{\text {plastic }}$

$\Delta_{\text {imp }}=\Delta_{\text {plastic }}=\theta_{p} \times L$

$\Delta_{\text {imp }}=\theta_{p} \times L$

Where $\Delta_{\text {elastic }}$ is the beam end displacement, $\Delta_{\text {imp }}$ is the displacement due to imposed interface rotation along with the member $\left(\theta_{\text {imp }}\right)$ of the precast frame. $\Delta_{\text {plastic }}$ is the beam end displacement of the monolithic frame due to plastic curvature over the plastic hinge. Therefore, the fixed beam-column rotation interface $\left(\theta_{p}\right)$ should represent the $\theta$ of the monolithic joint. After the beam-column rotation interface is fixed, the neutral axis depth (c) of the beam was guessed. After the beam-column rotation interface is fixed, the neutral axis depth (c) of the beam was guessed. Figure shows the precast ductile connection and the monolithic connection under plastic rotation according to Monolithic Beam Analogy (MBA).

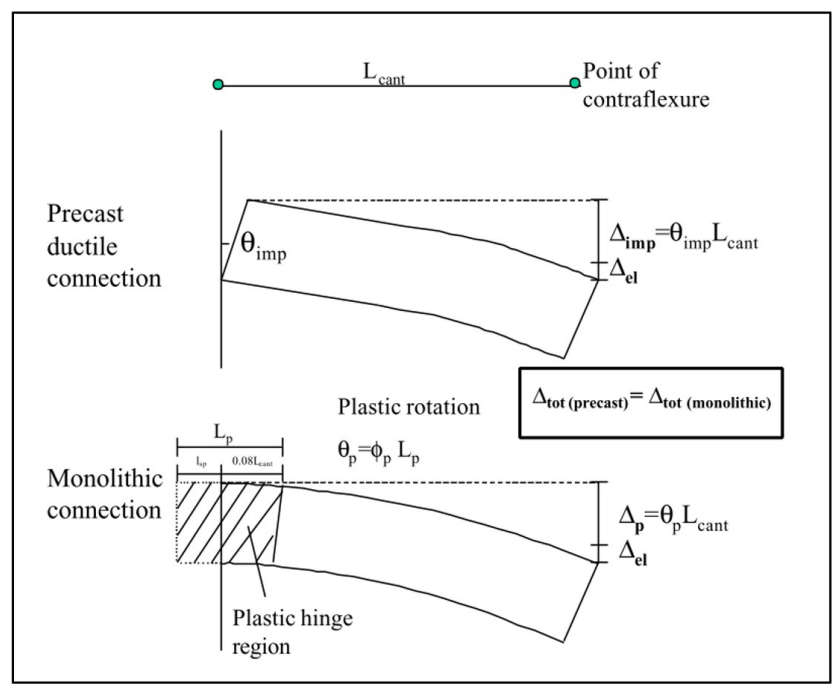

Figure 14: Monolithic Beam Analogy [11]

We can utilize in the monolithic case the ultimate and yielding curvature $\left(\phi_{\mathrm{u}}\right.$ and $\left.\phi_{\mathrm{y}}\right)$ concepts [16]: 
$\theta_{p}=\theta_{p}\left(\mathrm{~L}-\frac{\mathrm{L}_{\mathrm{p}}}{2}\right)=\left(\phi_{\mathrm{u}}-\phi_{\mathrm{y}}\right) \mathrm{L}_{\mathrm{p}}\left(\mathrm{L}-\frac{\mathrm{L}_{\mathrm{p}}}{2}\right)$

Where $L_{p}$ is the plastic hinge length. By combining Equation 13 and Equation 14, the following equations can be derived.

$\theta_{i m p} L=\left(\phi_{u}-\phi_{y}\right) L_{p}\left(L-\frac{L_{p}}{2}\right)$

$\left(\phi_{u}-\phi_{y}\right)=\frac{\left(\theta_{i m p} L\right)}{\left(L-\frac{L_{p}}{2}\right) L_{p}}$

$\phi_{u}=\frac{\varepsilon_{c}}{c}=\frac{\left(\theta_{i m p} L\right)}{\left(L-\frac{L_{p}}{2}\right) L_{p}}+\phi_{y}$

Therefore, by rearranging Equation 17, Equation 18 can be obtained to represent the value of concrete strain, $\varepsilon_{\mathrm{c}}$.

$\varepsilon_{C}=\left[\frac{\left(\theta_{i m p} L\right)}{\left(L-\frac{L p}{2}\right) L_{p}}+\phi_{y}\right] C$

Thus, the Equation 18 is simplified as follows:

$\varepsilon_{c}=f(c)$

Thus, a simple relationship between concrete strain, $\varepsilon_{c}$ and neutral axis position, $c$ is established. By using Equation 19 for the value of concrete strain, $\varepsilon_{c}$ the compression resultant force in concrete can be estimated using Equation 20 as follows:

$C=\varepsilon\left({ }_{c}, c\right)$

Step 5: Check forces equilibrium

The compression resultant in the concrete, $C$ is calculated from equilibrium considerations on the section as shown in Equation 21. Equilibrium must be reached between compression force in fuse bars, $C_{f}$, and compression resultant in the concrete, $C$.

$\mathrm{C}=\mathrm{C}_{\mathrm{f}}(21)$

$C_{f}$ is the compressive force of fuse bar acting as an external force and it is represented by $T_{\Delta}$. $T_{\Delta}$ is the tensile force due to the deformation of the beam and given by Equation 23 as below:

$C_{f}=T_{\Delta}$

$\mathrm{T}_{\Delta}=\mathrm{f}\left(\varepsilon_{\mathrm{f}}\right) \mathrm{A}_{\mathrm{f}}$

Thus,

$C_{f}=f\left(\varepsilon_{f}\right) A_{f}$

Step 6: Calculate moment and develop a moment-rotation envelope

The final step involves the calculation of the moment resistance capacity of the section that corresponds to the fixed rotation, $\theta$. This can be obtained by taking a moment through the mid-height of the section. In this study, the steps listed are repeated for drift range values between \pm 0.05 until $\pm 3.0 \%$ drift (expected maximum target drift). The process was carried out to establish a continuous moment-rotation envelope (analytical result) as shown in Figure 11(a) and Figure 11(b). 


\subsection{COMPARISON OF LATERAL STRENGTH CAPACITY}

The comparison of ultimate lateral strength capacity for two cycles between $\mathrm{CJ}-2 \mathrm{~B}$ specimen and $\mathrm{BC} 1-2 \mathrm{C}$ Specimen is required to determine the efficiency of these fuse bars placed inside the corner joint. Figure 15 shows the comparison of lateral strength capacity by representing by the skeleton curve between $\mathrm{CJ}-2 \mathrm{~B}$ specimen (dark black line) and BC1-2C Specimen (light black line) for Cycle 1 . The $\mathrm{CJ}-2 \mathrm{~B}$ Specimen with fuse bars has $\mathrm{H}_{\mathrm{u}}=90.39 \mathrm{kN}$ with the corresponding ultimate displacement $\Delta_{\mathrm{u}}$ of $42.22 \mathrm{~mm}$ at $1.5 \%$ drift in pushing direction before experiencing strength degradation at $1.75 \%$ and $2 \%$ drift. Meanwhile, $\mathrm{H}_{\mathrm{y}}$ is $35 \mathrm{kN}$ with the projection of yield displacement $\left(\Delta_{\mathrm{y}}\right)$ is $19 \mathrm{~mm}$. At $2 \%$ drift in pulling direction, the ultimate lateral capacity $\left(\mathrm{H}_{\mathrm{u}}\right)$ is $102 \mathrm{kN}$ with ultimate displacement $\left(\Delta_{\mathrm{u}}\right)$ is $-41.5 \mathrm{~mm}$. Meanwhile, $\mathrm{H}_{\mathrm{y}}$ was calculated at $-30 \mathrm{kN}$ and $\Delta_{\mathrm{y}}$ at $-18 \mathrm{~mm}$. For $\mathrm{BC} 1-2 \mathrm{C}$ Specimen, Cycle 1 in pushing direction has ultimate load $\left(F_{u}\right)$ of $36.1 \mathrm{kN}$ and $\Delta_{u}$ as $43.46 \mathrm{~mm}$. In pulling direction, the ultimate lateral capacity $(\mathrm{Hu})$ is $-79.5 \mathrm{kN}$ corresponding to ultimate displacement of $-36 \mathrm{~mm}$. It can be concluded that the ultimate strength capacity of corner beam-column joint with fuse bars has three times higher than corner joint without fuse bars. The main reason is because $\mathrm{CJ}-2 \mathrm{~B}$ Specimen has more percentage of reinforcement bars in the joint as compared to BC1-2C Specimen supported the study conducted by other researchers [22].

Figure 16 shows the comparison of lateral strength capacity between $\mathrm{CJ}-2 \mathrm{~B}$ and $\mathrm{BC} 1-2 \mathrm{C}$ Specimen for Cycle 2. For Cycle 2, $\mathrm{CJ}-2 \mathrm{~B}$ Specimen in pushing direction, $\mathrm{Hu}$ has $87.30 \mathrm{kN}$ and $\Delta \mathrm{u}$ as $34.26 \mathrm{~mm}$ at $1.25 \%$ drift and Hy was estimated as $32 \mathrm{kN}$ while $\Delta_{\mathrm{y}}$ is $16 \mathrm{~mm}$. $\mathrm{H}_{\mathrm{y}}$ and $\Delta_{\mathrm{y}}$ were estimated as $-25.15 \mathrm{kN}$ and $-16 \mathrm{~m}$ in pulling direction. Subsequently, the values of $\mathrm{Hu}$ and $\Delta \mathrm{u}$ in pulling direction are $-98.08 \mathrm{kN}$ and $-56.95 \mathrm{~mm}$ respectively. For BC1-2C Specimen at Cycle 2 in pushing direction, the ultimate strength capacity $\mathrm{Hu}$ is $33.33 \mathrm{kN}$ and ultimate lateral displacement $\Delta_{\mathrm{u}}$ is $41.96 \mathrm{~mm}$. In the pulling direction, Hu was estimated as $-71.36 \mathrm{kN}$ and $\Delta \mathrm{u}$ is taken as $-39.48 \mathrm{~mm}$. Therefore, it is evident that the joint with fuse bars can increase the lateral strength three times higher than without fuse bars in pushing direction. At the same time, joint with fuse bars can increase twice as compared without fuse bars. Thus, it is recommended to use fuse bars as mechanical energy dissipator to increase the lateral strength capacity and reduce the structural damage during moderate or strong earthquake excitations.

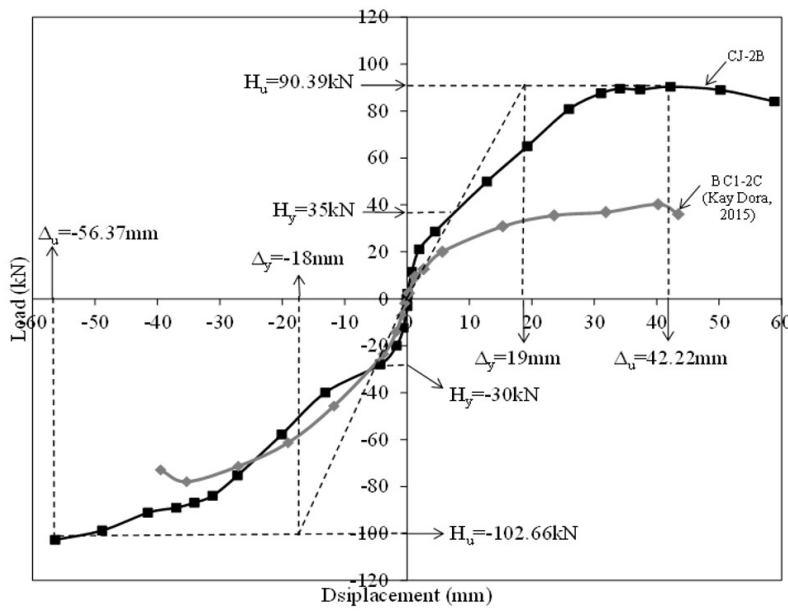

Figure 15: Comparison of ultimate strength capacity between $\mathrm{CJ}-2 \mathrm{~B}$ Specimen and BC1-2C Specimen for Cycle 1 using skeleton curve [21].

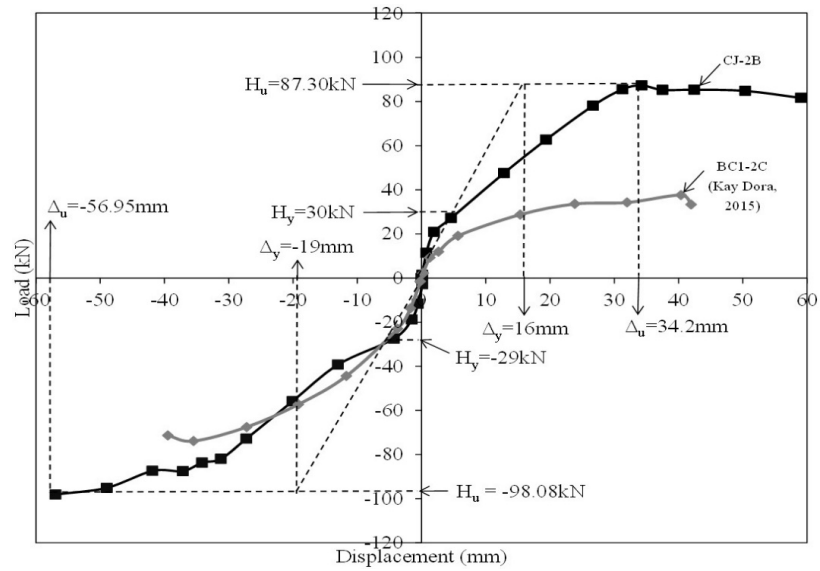

Figure 16: Comparison of ultimate strength capacity between $\mathrm{CJ}-2 \mathrm{~B}$ Specimen and BC1-2C Specimen for Cycle 1 using skeleton curve [21]. 
Table 2 shows the percentage comparison of ultimate lateral strength capacity between CJ-2B Specimen and BC12C Specimen in pushing and pulling direction for Cycle 1 and Cycle 2. It was found that joint with fuse bars has the lateral strength of corner joint increased up to $56 \%$ in pushing direction and $24 \%$ in pulling direction. Therefore, it can be concluded that corner joint with fuse bars can perform better than without fuse bars under in-plane lateral cyclic loading. The next comparison of seismic performance parameter is stiffness which will be discussed in the following section.

Table 2: Comparison of lateral strength capacity between CJ-2B Specimen and BC1-2C Specimen

\begin{tabular}{cccccc}
\hline & Direction & CJ-2B (with fuse bars) & & BC1-2C (without fuse bars) & Percentage Difference (\%) \\
\cline { 3 - 3 } \cline { 5 - 5 } Cycle 1 & Pushing & $\mathbf{H}_{\mathrm{u}}(\mathbf{k N})$ & 90.39 & $\mathbf{H}_{\mathrm{u}}(\mathbf{k N})$ & 55 \\
& Pulling & -102.66 & 40.32 & 24 \\
\multirow{2}{*}{ Cycle 2 } & Pushing & 87.30 & -77.93 & 56 \\
& Pulling & -98.08 & 37.61 & -73.89 & 24 \\
\hline
\end{tabular}

\subsection{COMPARISON STIFFNESS OF THE JOINT}

The generalized stiffness method takes the influence degree of the member on the general structural stiffness as the importance assessment index of the structural member. It is important to compare the stiffness of corner beam-column joint with and without fuse bars in order to make sure the joint remain in elastic region which experience minimal damages. The values of stiffness can be calculated by dividing the lateral load with displacement. There are two types of stiffness which will be measured in this study namely elastic stiffness ( $\left.K_{e}\right)$ and secant stiffness $\left(K_{s e c}\right)$. According to Sullivan, Calvi, \& Priestley [23], the stiffness of the structural system upon reaching yield load $\left(\mathrm{H}_{\mathrm{y}}\right)$ is known as the elastic stiffness, $\mathrm{K}_{\mathrm{e}}$. While in the inelastic range, the secant stiffness, $\mathrm{K}_{\mathrm{sec}}$ relates between the ultimate load $\left(\mathrm{H}_{\mathrm{u}}\right)$ and its corresponding ultimate displacement, $\Delta_{u}$. Figure $17(\mathrm{a})$ shows the graph of stiffness versus drift for CJ-2B Specimen for Cycle 1 while Figure 17(b) shows the graph of stiffness versus drift for Cycle 2. For comparing and analysing purposes, the stiffness degradation curves for each cycle in both directions were plotted in the same axis. It was found that the $K_{e}$ and $K_{s e c}$ for Cycle 1 and Cycle 2 exhibit similar pattern. These results directly affect the stiffness of the beam-column joint where upon yielding; the stiffness curve shows a steeper slope as compared after yielding. This phenomenon occurred because in the earlier drift (before yield), the stiffness of the beam-column joint depends on both concrete and reinforcement bars. Once the concrete cracked, the strength of the joint relies on the reinforcement bars which resulted in gradual decrease of stiffness. This result is supported and in-line with the study conducted by Vidovic et al. [24], which stated that the formation of cracks in concrete reduced the stiffness of the reinforced concrete elements and it occurred at loads much smaller than those that correspond to yielding of reinforcement and bearing capacity of elements. It can be concluded that the elastic stiffness has a higher value compared to the secant stiffness for both cycles in pushing and pulling directions.

Figure 18(a) and Figure 18(b) show the stiffness versus drifts curve for BC1-2C Specimen for Cycle 1 and Cycle 2, respectively. It was found that the corner joint without fuse bars have similar decreasing trend but at lower stiffness values. Table 3 compares the elastic and secant stiffness values for CJ-2B and BC1-2C in pushing and pulling directions. For Cycle 1 in pushing direction, the value of $\mathrm{K}_{\mathrm{e}}$ for $\mathrm{CJ}-2 \mathrm{~B}$ is 15.21 and 16.00 for Cycle 2 which are higher as compared to $\mathrm{BC} 1-2 \mathrm{C}$ which is 8.61 for Cycle 1 and 9.29 for Cycle 2 with percentage difference of $43.39 \%$ and $41.94 \%$, respectively. Subsequently, $\mathrm{K}_{\mathrm{sec}}$ for Cycle 1 of $\mathrm{CJ}-2 \mathrm{~B}$ and $\mathrm{BC} 1-2 \mathrm{C}$ are 3.05 and 2.78 , respectively in pulling direction and percentage difference of $8.85 \%$. A similar pattern also goes to Cycle 2 where $\mathrm{K}_{\mathrm{sec}}$ for $\mathrm{CJ}-2 \mathrm{~B}$ is 3.01 and 2.69 for $\mathrm{BC} 1-2 \mathrm{C}$ in pulling direction with percentage difference $10.63 \%$. Even though both of the specimen used the same concrete Grade 50 but it was found that Specimen CJ-2B has a higher value of $\mathrm{K}_{\mathrm{e}}$ because it was designed using Eurocode 8 embedded with fuse bars at the joint. This is because the stiffness of the structure is highly dependent on the modulus of elasticity of the concrete and the amount of the reinforcement bars in the corner beam-column joint. Thus, it can be concluded that the $\mathrm{K}_{\mathrm{e}}$ and $\mathrm{K}_{\mathrm{sec}}$ has a higher value for Specimen CJ-2B with fuse bars as compared to Specimen BC1-2C without fuse bars because it has a higher percentage of reinforcement bars in longitudinal and transverse directions. The next comparison of seismic performance parameter for corner beam-column joint is ductility which is explained in the following section. 


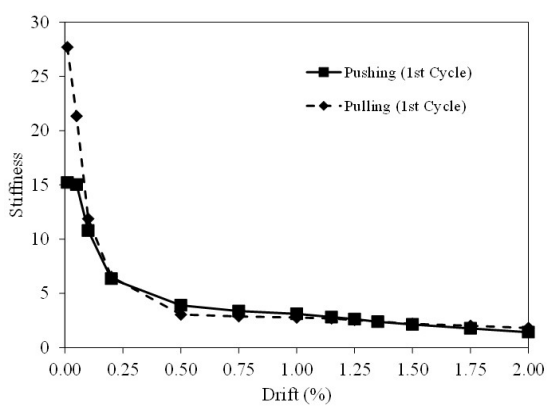

(a) Cycle 1

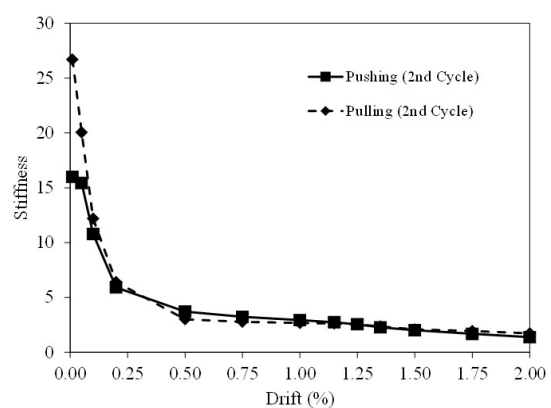

(b) Cycle 2

Figure 17: Stiffness of CJ-2B Specimen for (a) Cycle 1 and; (b) Cycle 2

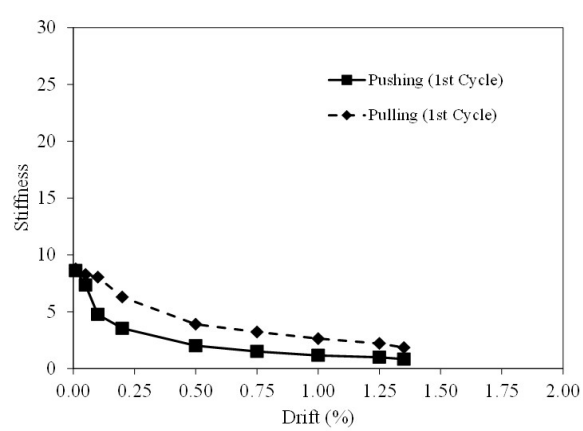

(a) Cycle 1

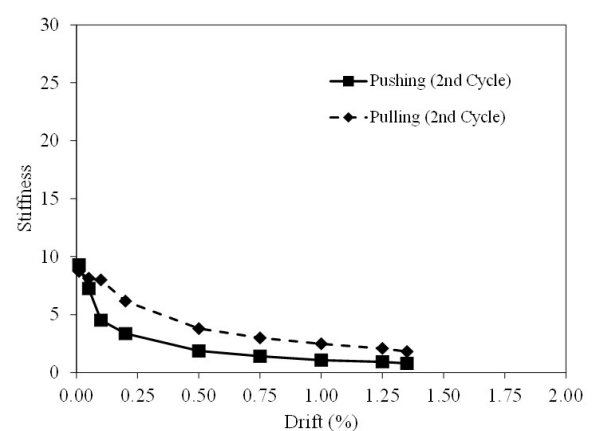

(b) Cycle 2

Figure 18: Stiffness of BC1-2C Specimen for (a) Cycle 1 and; (b) Cycle 2

Table 3: Comparison of $\mathrm{K}_{\mathrm{e}}$ and $\mathrm{K}_{\mathrm{sec}}$ between $\mathrm{CJ}-2 \mathrm{~B}$ Specimen and BC1-2C Specimen [21]

\begin{tabular}{|c|c|c|c|c|c|c|c|}
\hline \multirow[t]{2}{*}{ Cycle } & \multirow[t]{2}{*}{ Directions } & \multicolumn{2}{|c|}{ Elastic stiffness $\left(K_{e}\right)$} & \multirow{2}{*}{$\begin{array}{c}\text { Percentage } \\
\text { Difference }\end{array}$} & \multicolumn{2}{|c|}{ Secant stiffness $\left(K_{\text {sec }}\right)$} & \multirow{2}{*}{$\begin{array}{c}\text { Percentage Difference } \\
\text { (\%) }\end{array}$} \\
\hline & & CJ-2B & BC1-2C & & CJ-2B & BC1-2C & \\
\hline \multirow[t]{2}{*}{ Cycle 1} & Pushing & 15.21 & 8.61 & 43.39 & 3.90 & 1.12 & 71.82 \\
\hline & Pulling & 27.70 & 5.36 & 80.65 & 3.05 & 2.78 & 8.85 \\
\hline \multirow[t]{2}{*}{ Cycle 2} & Pushing & 16.00 & 9.29 & 41.94 & 3.71 & 0.99 & 73.31 \\
\hline & Pulling & 26.70 & 7.85 & 70.60 & 3.01 & 2.69 & 10.63 \\
\hline
\end{tabular}

\subsection{COMPARISON OF DUCTILITY}

Ductility is a very important seismic performance parameter in seismic design because it will determine whether the structural cannot survive or survive under earthquake attacks. The comparison of ductility of corner joint with fuse bars designed according to Eurocode 8 and without fuse bars designed using BS 8110 (non-seismic design) are determined herein. The displacement ductility of CJ-2B Specimen was calculated by taking the ratio of maximum displacement over yield displacement. Table 4 displays the ductility values for $\mathrm{CJ}-2 \mathrm{~B}$ Specimen in the pushing and pulling directions for both loading cycles. For Cycle 1, the maximum displacement ductility in the pushing and pulling direction are 3.10 and 3.13 respectively. While for Cycle 2, the maximum ductility in the pushing direction is 3.69 and pulling direction is 3.00 . This result is in good agreement with the values of ductility for structures with Ductility Class Medium [25]. On the order hand, BC1-2C Specimen has lower value of displacement ductility as compared to CJ-2B Specimen.

Table 5 shows the comparison values of displacement ductility between $\mathrm{CJ}-2 \mathrm{~B}$ and $\mathrm{BC} 1-2 \mathrm{C}$ specimens. The displacement ductility values for $\mathrm{BC} 1-2 \mathrm{C}$ for both cycles are less than 2 and located between 1.71 and 1.95 . For nonductile structures without fuse bars which designed using BS8110, the displacement ductility of the structures is less than 2.0 and categorized as Ductility Class Low (DCL) with peak ground acceleration less than $0.08 \mathrm{~g}$. Contradictory, the values of displacement ductility for specimen $\mathrm{CJ}-2 \mathrm{~B}$ are between 3.00 and 3.69. Therefore, it can be concluded that the corner 
joint with fuse bars can increase displacement ductility twice as compared with joint without fuse bars. The final seismic parameter to be compared is equivalent viscous damping which will be discussed in the following section.

Table 4: Displacement ductility for CJ-2B Specimen

\begin{tabular}{ccccc}
\hline Cycle & Direction & $\boldsymbol{\Delta}_{\max }(\mathbf{k N})$ & $\boldsymbol{\Delta}_{\mathbf{y}}(\mathbf{m m})$ & Ductility, $\boldsymbol{\mu}$ \\
\hline Cycle 1 & Pushing & 58.89 & 19.0 & 3.10 \\
& Pulling & -56.37 & -18.0 & 3.13 \\
\multirow{2}{*}{ Cycle 2 } & Pushing & 50.37 & 16.0 & 3.69 \\
& Pulling & -56.95 & -19.0 & 3.00 \\
\hline
\end{tabular}

Table 5: Comparison of ductility between corner joint $\mathrm{CJ}-2 \mathrm{~B}$ and $\mathrm{BCl}-2 \mathrm{~B}$ specimens

\begin{tabular}{|c|c|c|c|c|}
\hline \multirow{2}{*}{ Cycle } & \multirow{2}{*}{ Direction } & \multicolumn{2}{|c|}{ Ductility, $\mu$} & \multirow{2}{*}{ Difference (\%) } \\
\hline & & $\mathrm{CJ}-2 \mathrm{~B}$ & BC1-2C & \\
\hline \multirow[t]{2}{*}{ Cycle 1} & Pushing & 3.10 & 1.80 & 41.94 \\
\hline & Pulling & 3.13 & 1.71 & 45.37 \\
\hline \multirow[t]{2}{*}{ Cycle 2} & Pushing & 3.69 & 1.95 & 47.15 \\
\hline & Pulling & 3.00 & 1.73 & 42.33 \\
\hline
\end{tabular}

\subsection{COMPARISON OF EQUIVALENT VISCOUS DAMPING}

The amount of energy dissipated during testing can be calculated the total area under hysteresis loops. The values of equivalent viscous damping (乡eq) can be calculated using the following Equation 25 as follows [26]:

$\xi \mathrm{eq}=\frac{1}{4 \pi} \frac{E_{D}}{E_{\text {so }}} \times 100 \%$

where $E_{D}$ is the total area under the hysteresis loops and $E_{s o}$ is the strain energy under triangle area of load versus displacement. The hysteresis loops for each drift for both Cycle 1 and Cycle 2 were calculated and compared between two specimens. The comparison of viscous damping percentage between CJ-2B Specimen and BC1-2C Specimen is presented herein. Table 6 shows the comparison equivalent viscous damping between $C J-2 B$ Specimen and BC1-2C Specimen for Cycle 1 and Cycle 2. The maximum percentage of equivalent viscous damping for CJ-2B Specimen is $18.67 \%$ occurs at $0.05 \%$ drift at Cycle 2 . Meanwhile, the maximum percentage of equivalent viscous damping for $\mathrm{BC} 1-2 \mathrm{C}$ Specimen is $12.00 \%$ occurs at $0.75 \%$ drift at Cycle 1 . The graph of equivalent viscous damping versus drifts for corner joint with fuse bars (CJ-2B) and corner joint without fuse bars (BC1-2C) are shown in Figure 19 and Figure 20, respectively. By comparing both graphs, it can be seen that CJ-2B Specimen has a maximum equivalent viscous damping of $18.67 \%$ while BC1-2C Specimen has a maximum equivalent viscous damping of $12 \%$. However, the trends of these graphs for both specimens are differed from each other. The graph of equivalent viscous damping for CJ-2B Specimen shows a decreasing from $0.05 \%$ drift to $1.0 \%$ drift and followed by a gradual increase at later drift. While for BC1-2C Specimen, the equivalent viscous damping values increased from $0.05 \%$ to $1.0 \%$ drift and gradually decreased until $1.35 \%$ drift. Moreover, it can be noticed that the value of equivalent viscous damping is higher in the first cycle as compared to the second cycle. This is due to the fact that more energy is dissipated in the first cycle and the interaction between concrete and fuse bar is in stronger condition as compared in the second cycle. Generally, CJ-2B Specimen has lower equivalent viscous damping due to smaller hysteresis loops compared to BC1-2C Specimen. The value of equivalent viscous damping is highly dependent on the area of hysteresis loops under load versus displacement for energy dissipation ( $E_{D}$ ) and its strain energy $\left(E_{S O}\right)$. Furthermore, the areas under hysteresis loops for CJ-2B Specimen are lower than BC1-2C Specimen. Subsequently, the bigger area under hysteresis loops means that a lot of damages that occurred because these energies were absorbed in the corner beam-column joint. Therefore, the amount of equivalent viscous damping is lower in CJ-2B Specimen as compared to BC1-2C Specimen because the fuse bars in the corner beam-column joint could reduce the area under the hysteresis loops. 
Table 6: Comparison of equivalent viscous damping for $\mathrm{CJ}-2 \mathrm{~B}$ and $\mathrm{BC} 1-2 \mathrm{C}$ specimens

\begin{tabular}{|c|c|c|c|c|c|}
\hline \multirow{3}{*}{ Drift (\%) } & \multicolumn{2}{|c|}{ CJ-2B Specimen } & \multirow{3}{*}{ Drift (\%) } & \multicolumn{2}{|c|}{ BC1-2C Specimen } \\
\hline & 1st Cycle & 2nd Cycle & & 1 st Cycle & 2nd Cycle \\
\hline & $\zeta_{\text {eq }}(\%)$ & $\zeta_{\text {eq }}(\%)$ & & $\zeta_{\text {eq }}(\%)$ & $\zeta_{\text {eq }}(\%)$ \\
\hline 0.05 & 18.32 & 18.67 & 0.01 & 3.38 & 3.87 \\
\hline 0.10 & 14.15 & 14.14 & 0.05 & 3.41 & 3.19 \\
\hline 0.20 & 11.96 & 10.71 & 0.10 & 6.45 & 3.59 \\
\hline 0.50 & 8.35 & 6.33 & 0.20 & 6.72 & 3.88 \\
\hline 0.75 & 6.80 & 4.94 & 0.50 & 11.78 & 7.10 \\
\hline 1.00 & 5.58 & 4.24 & 0.75 & 12.00 & 10.12 \\
\hline 1.15 & 4.44 & 3.82 & 1.00 & 11.60 & 10.34 \\
\hline 1.25 & 4.53 & 3.85 & 1.25 & 11.38 & 9.15 \\
\hline 1.35 & 4.77 & 4.24 & 1.35 & 8.05 & 8.28 \\
\hline 1.50 & 5.46 & 5.40 & & & \\
\hline 1.75 & 6.99 & 6.03 & & & \\
\hline 2.00 & 6.16 & 5.54 & & & \\
\hline
\end{tabular}

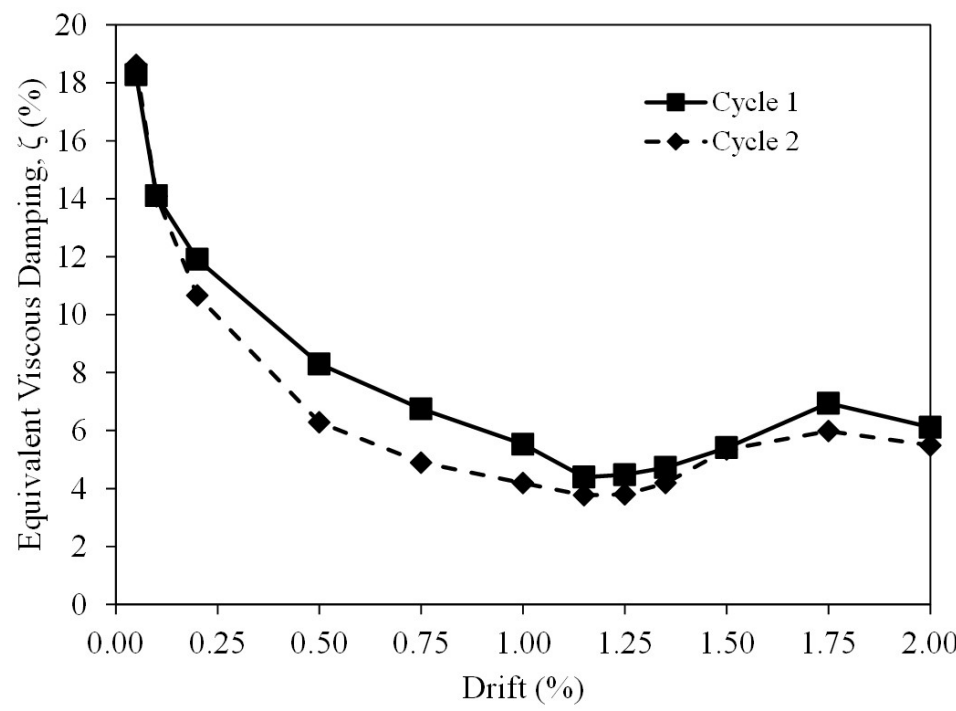

Figure 19: Equivalent viscous damping curve of CJ-2B Specimen

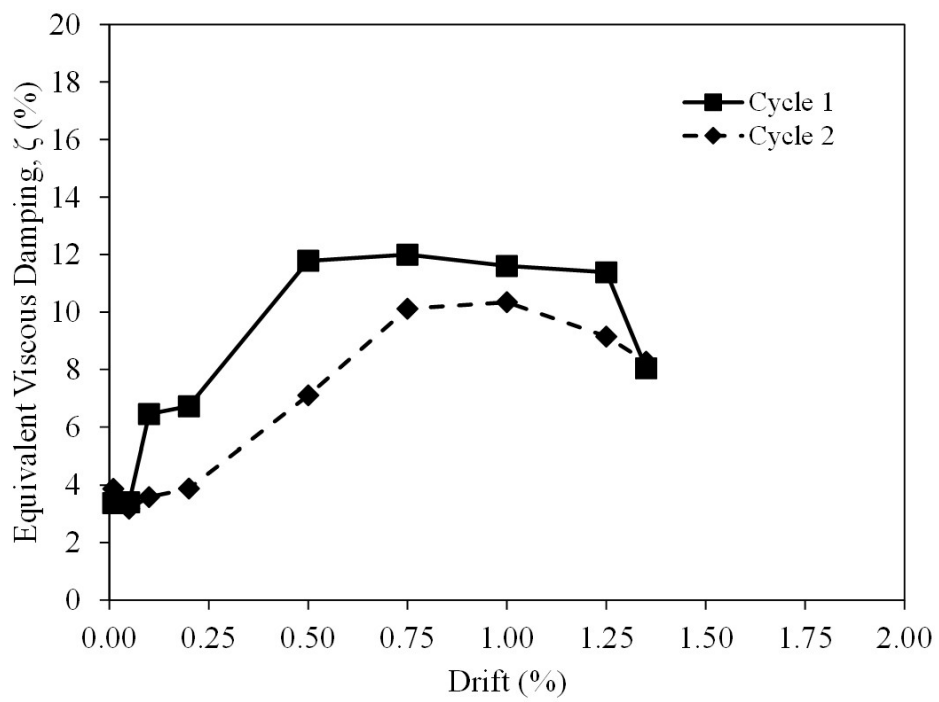

Figure 20: Equivalent viscous damping curves of BC1-2C Specimen 


\section{COMPARISON BETWEEN EXPERIMENTAL AND MODELLING OF CJ-2B}

\section{SPECIMEN AND BC1-2C SPECIMEN}

It is important to validate the hysteresis loops between experimental and modelling results because the modelling hysteresis loops will be used as input data file to run Ruaumoko 2D program using nonlinear time history analysis under different level of earthquake excitation. In this study, the comparison of experimental hysteresis loops of CJ-2B Specimen and BC1-2C Specimen were made with modelling hysteresis loops elected from Appendix Ruaumoko 2D Manual [27]. The Hysteresis Rule number 44 (IHYST=44) known as Pampanin Reinforced Concrete (RC) Beam-Column Hysteresis Model was chosen for both specimens because they are having similar patterns. Figure 21 shows the input parameters require by Pampanin RC Beam-column Hysteresis which need to be calculated based on experimental hysteresis loops.

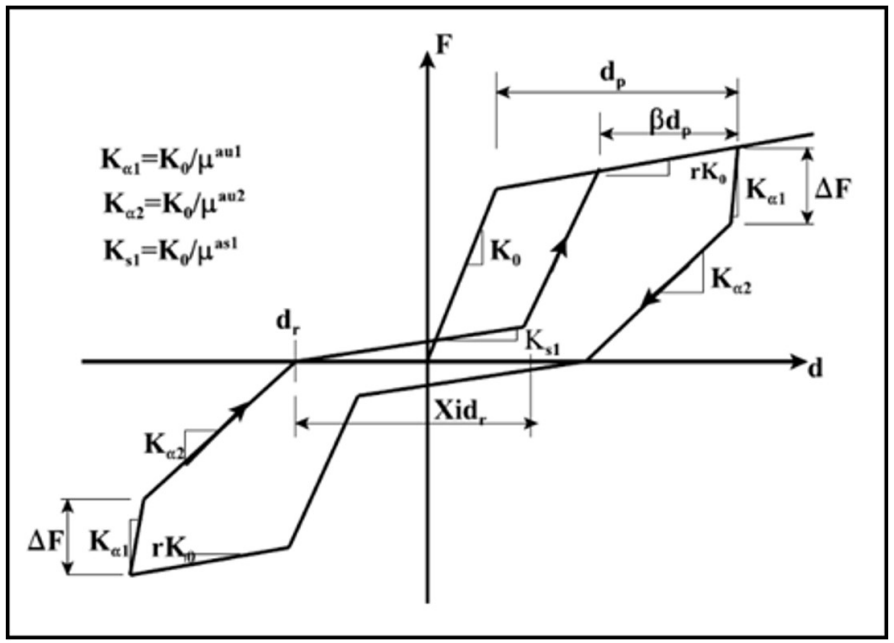

Figure 21: The parameters required for Pampanin RC Beam-column Hysteresis (IHYST=44)

The parameter of elastic initial stiffness $\left(K_{0}\right)$ as shown in Figure 21 can be calculated using Equation 26 and bi-linear factor $(r)$ can be estimated using Equation 27 based on the experimental hysteresis loops. These two equations are as follows:

$K_{0}=\frac{\left(Y_{2}-Y_{1}\right)}{\left(X_{2}-X_{1}\right)}$

$r=\frac{\left(Y_{2}-Y_{1}\right)}{\left(X_{2}-X_{1}\right)} \times \frac{1}{K_{0}}$

Where, $\mathrm{X}_{1}$ is the coordinate at Node 1 in $\mathrm{X}$ - $\mathrm{X}$ axis; $\mathrm{X}_{2}$ is the coordinate at Node 2 in $\mathrm{X}$ - $\mathrm{X}$ axis; $\mathrm{Y}_{1}$ is the coordinate at Node 1 in $y-y$ axis; and $Y_{2}$ is the coordinate at Node 2 in $y-y$ axis. The stiffness degradation parameters of hysteresis loop model for initial unloading stiffness $\left(K_{\propto 1}\right)$ using Equation 28, final unloading stiffness using Equation 29 and slip stiffness using Equation 30. These equations are as listed below:

$K_{\propto 1}=K_{0} / \mu^{a u 1}$

$K_{\propto 2}=K_{0} / \mu^{a u 2}$

$K_{s 1}=K_{0} / \mu^{a s 1}$

Where $\mu_{\mathrm{au} 1}$ is the ductility with initial unloading power factor; $\mu_{\mathrm{au} 2}$ is the ductility with final unloading power factor and $\mu_{\text {as1 }}$ is the ductility with reloading power factor.

Table 7 presents the input parameters of Pampanin Reinforced Concrete (RC) Beam-Column Hysteresis Model (IHYST $=44$ ) which used to model the hysteresis loops for BC1-2C Specimen and CJ-2B Specimen using Equation 26 until Equation 30. 
Table 7: Input parameters for BC1-2C Specimen and CJ-2B Specimen

\begin{tabular}{|c|c|c|}
\hline \multirow{2}{*}{ PARAMETERS } & \multicolumn{2}{|c|}{ SPECIMEN } \\
\hline & BC1-2C & CJ-2B \\
\hline \multicolumn{3}{|c|}{ Parameters obtained from the hysteresis loops of the experimental result. } \\
\hline i. Stiffness, $\mathrm{K}_{\mathrm{o}}$ & 2 & 5 \\
\hline ii. Bi-linear factor, $r$ & 0.21 & 0.26 \\
\hline iii. Positive yield force, $\mathrm{P}+$ & 32 & 67.79 \\
\hline iv. Negative yield force, $\mathrm{P}$ - & -75 & -77 \\
\hline Hysteresis Rule Choice & \multicolumn{2}{|c|}{44 (Pampanin Reinforced Concrete Beam-Column Joint Hysteresis) } \\
\hline Strength Degrading Choice (ILOS) & \multicolumn{2}{|c|}{1 (Strength loss in each direction is a function of the ductility in that direction) } \\
\hline \multicolumn{3}{|c|}{ Degrading Strength Parameters: } \\
\hline i. Ductility at which degradation begins & 1.7 & 1.2 \\
\hline ii. Ductility at which degradation stops & 2 & 2.8 \\
\hline $\begin{array}{l}\text { iii. Residual strength as a fraction of the initial yield } \\
\text { strength }\end{array}$ & 0.9 & 0.3 \\
\hline iv. Ductility at 0.01 initial strength & 0 & 0 \\
\hline \multicolumn{3}{|c|}{ Pampanin RC Joint rule: } \\
\hline i. Reloading Factor Option, IOP & 2 & 2 \\
\hline ii. Slip Stiffness Power Factor, As1 & 1.5 & 1.5 \\
\hline iii. Reloading Slip Factor, Xi & 1.5 & 1.5 \\
\hline iv. Initial Unloading Power Factor, Au1 & -0.8 & 0 \\
\hline v. Final Unloading Power Factor, Au2 & 0.3 & 0.3 \\
\hline vi. Unloading Force Factor, DeltaF & 40 & 20 \\
\hline vii. Reloading Factor, Beta & -0.6 & -0.3 \\
\hline Plot sub-divisions & \multicolumn{2}{|c|}{5} \\
\hline Initial displacement & \multicolumn{2}{|c|}{0} \\
\hline \multirow[t]{2}{*}{ History choice and scale } & \multicolumn{2}{|c|}{1 (Built-in lab-test-like displacement history) } \\
\hline & \multicolumn{2}{|c|}{1.0 (Scale) } \\
\hline
\end{tabular}

Figure 22 shows the comparison of hysteresis loops between experimental and modelling for CJ-2B Specimen with fuse bars which had been tested under in-plane lateral cyclic loading. The solid line represents the modelled hysteresis loops while the dotted line represents the experimental hysteresis loops. The rule incorporated allowed pinching, and therefore a reasonable fit was achieved. Although a similar behaviour was shown between all the hysteresis loops, there are still some discrepancies between them. It was detected that the shape of modelling hysteresis loops is slightly bigger than experimental hysteresis loops. Figure 23 shows the comparison of hysteresis loops between experimental and modelling for BC1-2C Specimen joint without fuse bars. The comparison of lateral strength capacity, stiffness, ductility and equivalent viscous damping between experimental and modelling for these two specimens.

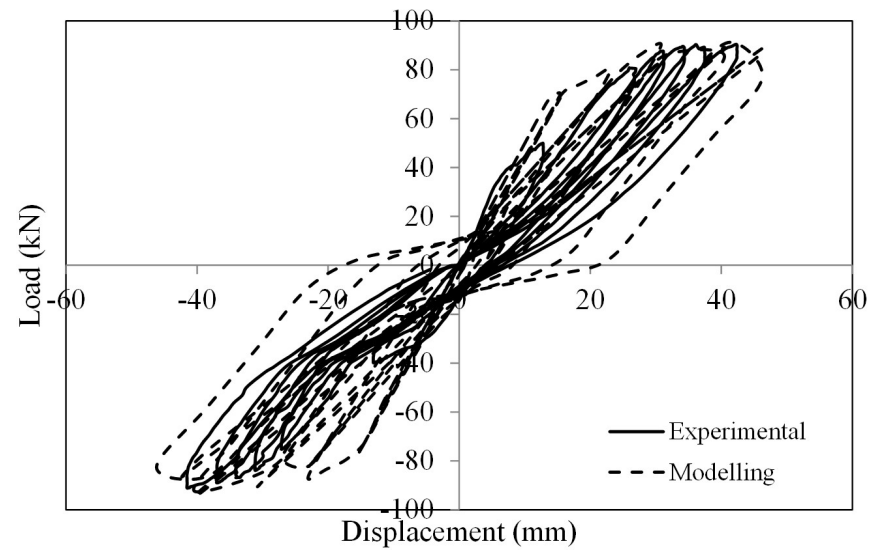

Figure 22: Comparison between experimental and modelling hysteresis loops of CJ-2B. 


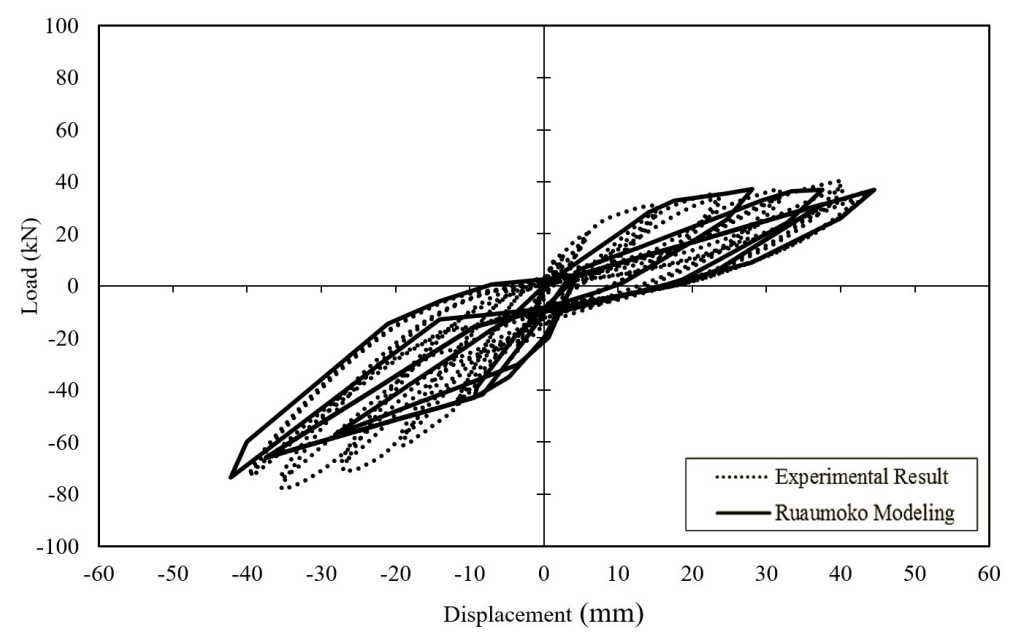

Figure 23: Comparison between experimental and modelling hysteresis loops of BC1-2C.

Based on Figure 22 and Figure 23, the percentage difference between experimental and modelling results were calculated for each parameter namely lateral strength capacity, stiffness, ductility and equivalent viscous damping. Subsequently, Table 8 shows the comparison of these seismic performance parameters between experimental hysteresis loops and modelling hysteresis loops in pushing direction for CJ-2B Specimen and BC1-2C Specimen. It can be clearly seen that the percentage differences for lateral strength capacity are $3.54 \%$ and $2.35 \%$, ductility are $8 \%$ and $11.74 \%$, stiffness are $8.33 \%$ and $12.07 \%$ and equivalent viscous damping are $10.73 \%$ and $3.24 \%$ for CJ-2B Specimen and BC1-2C Specimen, respectively. There are quite good agreement and acceptable correlation of percentage differences for these parameters which lies ranging from $2 \%$ and $20 \%$ [28]. The small difference between them because the modelling hysteresis loops are a little bit fatter than the experimental hysteresis loops. The HYSTERES Program tends to overestimate the results, however, the results are still reasonable to be used in Ruaumoko 2D for dynamic analysis since the requirement is only from the overall shape and behaviour of the hysteresis loops. This phenomenon occurs due to the fact that during the experimental work, there are a lot of energy was released to the surrounding under friction and kinetic energy. The untighten screw between foundation beam and strong floor could contribute to the sloppiness of the experimental hysteresis loops and friction to occur. The modelling confirmed that The Hysteresis Rule number 44 (Pampanin Reinforced Concrete Beam-Column Hysteresis) is acceptable in modelling the hysteresis loops of CJ-2B and BC1-2C. It can be concluded that all the seismic parameters such as lateral strength capacity, ductility, stiffness and equivalent viscous damping have bigger values for specimen $\mathrm{CJ}-2 \mathrm{~B}$ as compared with $\mathrm{BC} 1-2 \mathrm{C}$.

Table 8: Comparison of lateral strength, ductility, stiffness and equivalent viscous damping for CJ-2B Specimen and BC1-2C Specimen

\begin{tabular}{|c|c|c|c|c|c|c|}
\hline \multirow[b]{2}{*}{ Parameters } & \multicolumn{3}{|c|}{ CJ-2B Specimen } & \multicolumn{3}{|c|}{ BC1-2C Specimen } \\
\hline & $\begin{array}{l}\text { Experiment } \\
\text { Results }\end{array}$ & $\begin{array}{l}\text { Modelling } \\
\text { Results }\end{array}$ & $\begin{array}{l}\text { Percentage } \\
\text { Difference }\end{array}$ & $\begin{array}{l}\text { Experiment } \\
\text { Results }\end{array}$ & $\begin{array}{l}\text { Modelling } \\
\text { Results }\end{array}$ & $\begin{array}{l}\text { Percentage } \\
\text { Difference }\end{array}$ \\
\hline $\begin{array}{c}\text { Ultimate lateral Strength } \\
\text { Capacity (kN) }\end{array}$ & 90.39 & 93.71 & 3.54 & 36.10 & 36.97 & 2.35 \\
\hline Ductility & 3.10 & 2.76 & 10.96 & 1.80 & 1.70 & 5.55 \\
\hline Stiffness (kN/mm) & 1.43 & 1.56 & 8.33 & 1.16 & 1.47 & 12.07 \\
\hline Equivalent Viscous Damping (\%) & 6.99 & 7.83 & 10.73 & 11.60 & 12.00 & 3.34 \\
\hline
\end{tabular}

\section{DISCUSSIONS}

The corner beam-column joint is the most vulnerable structural element in reinforced concrete building under earthquake attack which designed using non-seismic code of practice. Hence, this study focuses on improving the seismic performance of corner beam-column joint by incorporating fuse bars and designed using current seismic code of practice (Eurocode 8). Two types of corner beam-column joints namely CJ-2B Specimen and BC1-2C Specimen were designed, constructed, tested, analyzed and modeled using HYSTERES program. Pampanin Reinforced Concrete (RC) Beam-Column Hysteresis Model (IHYST=44) was chosen to represent experimental hysteresis loops for these two specimens using 
different input parameters. The input parameters were used to model these hysteresis loops and calculate the seismic performance parameters known as ultimate lateral strength capacity, ductility, stiffness and equivalent viscous damping. These four parameters are very important in designing the corner beam-column joint with fuse bars subjected to ground motions.

The ultimate lateral strength capacities for both specimens can be obtained from skeleton curves as shown in Figure 15 and Figure 16. These skeleton curves are important index for assessing the seismic performance of structural element such as beam-column joint as well as a significant basis for determining the feature points in restoring force model for such elements. Furthermore, the analytical result or pushover curve as shown in Figure 11(a) and (b) are mapped with capacity design spectrum in determining the 'performance point' where the demand curve and capacity curve meet with each other. The performance point is an indicator to show the survivability of elements or members of the structures under different level of earthquakes.

Ductility is the key parameter in designing structural element or structure to cater for seismic load as provided in Eurocode 8. There are three types of dissipation classes in Eurocode 8 namely Ductility Class Low (DCL), Ductility Class Medium (DCM) and Ductility Class High (DCH). It is evident that the ductility for CJ-2B Specimen is higher than BC1-2C Specimen as shown in Table 8. Therefore, CJ-2B Specimen is classified as Ductility Class Medium with ductility of 3.10 and CJ-2B Specimen is categorized as Ductility Class Low because the value of ductility is 1.80 . Ductility Class Low behaves in brittle manner and the resistance to earthquake loading is achieved through the strength of the structure rather than its ductility. Meanwhile, Ductility Class Medium in which quite high levels of plasticity are permitted with corresponding design and detailing requirement are imposed. Hence, the corner beam-column joint of frame is highly stressed region with quite complex reinforcement detailing including fuse bars.

Stiffness is another important seismic performance parameter in designing corner beam-column joint under Direct Displacement Based Design (DDBD). The elastic stiffness, secant stiffness and effective stiffness can be calculated from two models of hysteresis loops. The effective stiffness is used to calculate the base shear capacity using Single Degree of Freedom (SDOF) based on the target displacement. The member forces in the structures were redistributed corresponding to calculate base shear before designing the structural elements such as beam-column joints, columns, beams and others.

Equivalent viscous damping is a significant parameter in determining the amount of energy dissipated during earthquake. Under DDBD, a graph of equivalent viscous damping versus ductility is plotted for steel frame, concrete frame and structural frame. Then, the targeted displacement is projected to calculate equivalent viscous damping to determine the period which used to construct design displacement response spectra. Thus, the displacement response spectrum is used by building designer to design fuse bar to be ductile and yield earlier than the brittle link is refers to the beam.

\section{CONCLUSIONS AND RECOMMENDATIONS}

Based on the comparison of seismic behaviour and hysteretic response of CJ-2B Specimen with fuse bars and BC12C Specimen without fuse bars under in-plane lateral cyclic loading, the following conclusions and recommendation can be drawn as follows:

1. CJ-2B Specimen can withstand an ultimate load of up to $88.85 \mathrm{kN}$ in pushing direction and $-100.37 \mathrm{kN}$ in pulling direction before experiencing strength degradation and these values are bigger than BC1-2C Specimen.

2. From the in-plane lateral cyclic testing it was observed that $\mathrm{CJ}-2 \mathrm{~B}$ Specimen sustained up to $\pm 2 \%$ drift, however, BC1-2C Specimen can sustain up to $\pm 1.35 \%$ drift.

3. The formation of cracks near the beam-column joint causing the stiffness to reduce significantly.

4. However, the beam-column joint was proven to have medium class ductility (DCM).

5. The equivalent viscous damping shows an increasing trend with an average damping ratio of say $6.99 \%$. As for numerical work, the selection of Pampanin RC Hysteresis Loops is deemed suitable for modeling the analytical hysteresis loops. Therefore, it can be concluded that the equivalent viscous damping for the seismic designed CJ-2B Specimen with the addition of $13 \mathrm{~mm}$ reduced diameter fuse bar under DCM (PGA $=0.12 \mathrm{~g}$ ) is $6.99 \%$.

6. There are quite good agreement between experimental and modeling results with percentage differences of lateral strength capacity, ductility, stiffness and ductility between them between $2 \%$ and $20 \%$ for CJ-2B Specimen and BC12C Specimen. 
7. BC1-2C Specimen which designed in accordance to BS8110 can only survive under PGA less than 0.08g which classified as Ductility Class Low (DCL).

8. Fuse bars made from high yield reinforcement bars which installed in $\mathrm{CJ}-2 \mathrm{~B}$ Specimen is considered as green infrastructural material and the most economical material used to reduce the structural damage during moderate and strong earthquake. Furthermore, fuse bars can be replaced after earthquake if suffered severe damage provided they are installed externally to corner beam-column joint.

\section{ACKNOWLEDGEMENTS}

Special thank goes to Malaysian of Higher Education of Malaysia (MOHE), Putrajaya, Malaysia who fund this research work under Fundamental Research Grants with file No: 600-RMI/FRGS 5/3 (0091/2016) and RMI (Research Management Institute) for managing this research work in the most efficient ways. Gratitude and appreciation to the laboratory staff members for their invaluable assistance during the course of this experimental research work.

Author contributions: Conceptualization, NHA Hamid; Methodology, ND Hadi; Investigation, Y Sutopo; Funding Acquisition, NA Zainudin; Software, IF Azmi; Validation, R Hassan; Visualization, B Chao; Writing-original draft, ND Hadi; Writing-review \& editing, NHA Hamid.

Editor: Pablo Andrés Muñoz Rojas

\section{REFERENCES}

[1] Goodfellow, R., Pinho, R., Salama, A., \& M.Hancock. Applications of fuse inserts in seismic design of reinforced concrete structures. Transactions on the Built Environment, 1995, 8, 1-3.

[2] Buckle, I.G., Passive Control Of Structures For Seismic Loads. Bulletin of the New Zealand Society for Earthquake Engineering, 2000, 33(3), 209-221.

[3] Hamid, N. H. A., \& Mander, J. B., Lateral Seismic Perfomance Of Mult-Panel Precast Hollow Core Walls Subjected To QuasiStatic Cyclic Loading. Journal of Structural Engineering Vol., 2010, 136(7):795-804

[4] Pampanin, S. (2010). “Damage-Control Self-Centering Structures: From Laboratory Testing to On-site Applications,” M.N. Fardis (ed.), Advances in Performance-Based Earthquake Engineering, Geotechnical, Geological, and Earthquake Engineering 2010, 13:297-308.

[5] Farrokhi, H., Danesh, F., and Eshghi, S, A Modified Moment Resisting Connection for Ductile Steel Frames (Numerical and Experimental Investigation), Journal of Constructional Steel Research, 2009, 65.10/11, 2040-2049.

[6] Hadi, N.D. and Hamid, N.H., Verification of Experimental Hysteresis Loops for Exterior Beam-Column Joint Under Lateral Cyclic Load, IOP Conference Series: Earth and Environmental Science, 2021, 644(1):012034.

[7] Calado, L., Proença, J. M., Espinha, M., \& Castiglioni, C. A., Hysteretic Behaviour Of Dissipative Bolted Fuses For Earthquake Resistant Steel Frames. Journal of Constructional Steel Research, 2013, 85:151-162.

[8] El-Bahey, S., \& Bruneau, M., Structural Fuse Concept For Bridges, Proceedings of the 9th U.S. National and 10th Canadian Conference on Earthquake Engineering, 2010, 1302.

[9] Rahman, A. M., \& Restrepo, J. I., Seismic Performance of Self-Centering Structural Walls Incorporating Energy Dissipators Journal of Structural Engineering 2007, 133(11):12-23.

[10] Palermo, Alessandro, Pampanin, S., \& Carr, A. (2005). Efficiency Of Simplified Alternative Modelling Approaches To Predict The Seismic Response Of Precast Concrete Hybrid Systems. Keep Concrete Attractive - Proceedings of the Fib Symposium 2005, 2, 1083-1088.

[11] Pampanin, S., Magenes, G., \& Carr, A., Modeling Of Shear Hinge Mechanism In Poorly Detailed R.C Beam-Column Joints. University of Canterbury, Research Repository, 2003, 5-8.

[12] Shafaei, J., Hosseini, A., Marefat, M. S., \& Ingham, J. Rehabilitation Of Earthquake Damaged External RC Beam-Column Joints, 2014 NZSEE Conference, 2014. 
[13] Kay Dora, A. G., Tukiar, M. A., Hamid, N. H., Yee, H. M., \& Nurjuhanah, J., Assessment Of Precast Beam-Column Exterior Joint Subject To Design Basis Earthquake (DBE) And Maximum Considered Earthquake (MCE) Using Fragility Curve. AIP Conference Proceedings, 2016, 1774(1).

[14] Garcia, R., Jemaa, Y., Helal, Y., Guadagnini, M., \& Pilakoutas, K., Seismic Strengthening of Severely Damaged Beam-Column RC Joints Using CFRP, Journal of Composites for Construction, 2014, 18(2), 04013048.

[15] N.D. Hadi, A.G. Kay Dora and N.H. Hamid, Comparison of Seismic Performance Between Interior Beam-column Joint Designed Using BS8110 and Eurocode 8, Chapter in Book, INCIEC2015, ISBN No: 978-981-10-0155-0, 209-220.

[16] Paulay, T., and Priestley, M.J.N., (1992), Seismic Design of Reinforced Concrete and Masonry Buildings, ISBN No: 9780471549154, Publisher: John Wiley \& Sons. Inc.

[17] European Committee for Standardization (2004b). EN 1998-1-1:Eurocode 8, Design of structures for earthquake resistance. Part 1: General rules, seismic actions and rules for buildings.

[18] Landolfo, F., Mazzolani, Dubina, D., Silva, L.S. (2017), Design of Steel Structures for Buildings in Seismic Areas, ISBN No: 978-3-433-03010-3, Publisher: ECCS Press/Ernst \& Sohn, Wiley.

[19] Vargas, R., \& Bruneau, M. (2005). Investigation of the Structural Fuse Concept. Computer Science.

[20] Rahmzadeh, A., \& Iqbal, A. (2018). Study Of Replaceable Energy Dissipators For Self-Centering Structure. Eleventh U.S. National Conference on Earthquake Engineering, Integrating Science, Engineering \& Policy, June 25-29 2018, Los Angeles, California, United States of America.

[21] Kay Dora, A. G. (2015). Full-Scale Precast Non- Seismic Beam-Column Joints With Corbels Under in-Plane Lateral Cyclic Loading, PhD Thesis, Faculty of Civil Engineering, Universiti Teknologi Mara, Shah Alam, Selangor, Malaysia

[22] Abdelwahed, B., Belkaseem, B. and Vantomme, J. (2018), Reinforced Concrete Beam-column Inverted Knee Joint Behaviour after Ground Corner Column Loss-Numerical Analysis, Latin American Journal of Solids and Structures, 15(10), pp 115.

[23] Sullivan, T J, Calvi, G. M., \& Priestley, M. J. N. (2004). Initial Stiffness Versus Secant Stiffness in Displacement Based Design. 13th World Conference on Earthquake Engineering, 2888.

[24] Vidovic, D., Grandic, D., \& Sculac, P. (2012). Effective Stiffness For Structural Analysis Of buildngs In Earthquake. 4th Internatonal Conference Civil Engineering-Science And Practice, February, 20-24.

[25] Azimi, M., Adnan, A., Tahir, M.M, Mohd Sam, A.R., and Abd Razak, S.M. (2014), Seismic Performance of Ductility Classes Medium RC Beam-column Connections with Continuous Rectangular Spiral Transverse Reinforcements, Latin American Journals of Solids and Structures, 12(4), pp 1-21.

[26] Chopra, A. K. (2012). Dynamics of structures: Theory and Applications to Earthquake Engineering, $4^{\text {th }}$ Edition, ISBN-10: 0273774247, Pearson Education Publisher.

[27] Carr, A.J., (2007), Ruaumoko Manual, Volume 5: Appendices, University of Canterbury, Christchurch, New Zealand.

[28] Oberkampf, W.L. and Barone, M.F. (2006), Measures of Agreement Between Computation and Experiment: Validation Metrics: Journal of Computational Physics, 217(2006), pp 5-36. 